\title{
Design of a High Power, LCC-Compensated, Dynamic, Wireless Electric Vehicle Charging System with Improved Misalignment Tolerance
}

\author{
Eiman ElGhanam $(\mathbb{D}$, Mohamed Hassan *(D) and Ahmed Osman \\ Department of Electrical Engineering, American University of Sharjah, P.O. Box 26666 Sharjah, UAE; \\ eelghanam@aus.edu (E.E.); aosmanahmed@aus.edu (A.O.) \\ * Correspondence: mshassan@aus.edu
}

Citation: ElGhanam, E.; Hassan, M.; Osman, A. Design of a High Power LCC-Compensated Dynamic Wireless Electric Vehicle Charging System with Improved Misalignment Tolerance. Energies 2021, 14, 885. https://doi.org/10.3390/en14040885

Academic Editor: Chunhua Liu Received: 21 December 2020 Accepted: 31 December 2020 Published: 8 February 2021

Publisher's Note: MDPI stays neutral with regard to jurisdictional clai$\mathrm{ms}$ in published maps and institutional affiliations.

Copyright: ( 2021 by the authors. Licensee MDPI, Basel, Switzerland. This article is an open access article distributed under the terms and conditions of the Creative Commons Attribution (CC BY) license (https:// creativecommons.org/licenses/by/ $4.0 /)$.

\begin{abstract}
Dynamic wireless power transfer (DWPT) systems are becoming increasingly important for on-the-move electric vehicle (EV) charging solutions, to overcome range anxiety and compensate for the consumed energy while the EV is in motion. In this work, a DWPT EV charging system is proposed to be implemented on a straight road stretch such that it provides the moving EV with energy at a rate of $308 \mathrm{Wh} / \mathrm{km}$. This rate is expected to compensate for the vehicle's average energy consumption and allow for additional energy storage in the EV battery. The proposed charging system operates at an average power transfer efficiency that is higher than $90 \%$ and provides good lateral misalignment tolerance up to $\pm 200 \mathrm{~mm}$. Details of the proposed system's design are presented in this paper, including EV specifications, inductive link and compensation network design and power electronic circuitry.
\end{abstract}

Keywords: electric vehicle; dynamic wireless power transfer; power transfer efficiency; compensation network; misalignment tolerance; charging control

\section{Introduction}

The design of efficient wireless electric vehicle (EV) chargers is one of the most extensively addressed research topics in transportation electrification and intelligent transportation systems (ITS). This is because the use of wired chargers introduces a set of limitations that degrade the reliability of these environmentally-friendly vehicles and hinder their adoption by the general public. Plug-in electric vehicles (PEVs), i.e., wire-charged EVs, need to be physically connected to charging sockets to charge their batteries, which introduces high risks of electrocution due to bare wires, harsh weather conditions, etc. [1]. This has motivated research efforts towards wireless charging solutions that eliminate this physical connectivity and ease the charging process [2,3]. Nevertheless, wireless EV charging systems introduce a different set of challenges, which are mainly concerned with the impact of the charging magnetic fields on the human body for humans inside and surrounding the wirelessly-charged vehicle. The IEEE C95.1 Standard for Safety Levels with Respect to Human Exposure to Radio Frequency Electromagnetic Fields [4] and the International Commission on Non-Ionizing Radiation Protection (ICNIRP) 2010 Guidelines for Limiting Exposure to Time-Varying Electric and Magnetic Fields [5] both define a maximum permissible human exposure to a magnetic field density of $27 \mu \mathrm{T}$ rms, assuming continuous charging fields. This safety exposure limit is acknowledged by the Society of Automotive Engineers (SAE) in their J2954 standard [6] in which the specifications of stationary wireless EV chargers are defined. The SAE J2954 standard proposes the use of resonant inductive power transfer (RIPT) to wirelessly couple the necessary power to charge the EV battery without exceeding the maximum magnetic field limit for safe human exposure. 
Hence, despite their advantages over wired charging systems, stationary EV chargers can only provide EV users with as much energy as the EV battery can hold for a single uninterrupted journey. This driving range limitation, along with the associated anxiety experienced by EV owners, has motivated researchers to investigate the feasibility of dynamic wireless charging (DWC) systems [7-10]. Such charging systems are expected to supply moving EVs with power during their motion, and hence compensate for the energy consumed by the EVs without depleting their batteries. In addition, implementing dynamic wireless power transfer (DWPT) systems along a city's roads enables the use of smaller, and hence lighter and cheaper EV batteries that are rarely fully depleted and thus expected to live longer. Nevertheless, the design of an optimal DWPT system needs to acknowledge the tradeoff between the power transfer efficiency, the charging power levels, the energy demand of the traveling EVs and the associated costs of power generation, infrastructure deployment, etc.

The RIPT system employs concepts of Ampere's and Faraday's laws by utilizing an alternating magnetic field in one coil, namely, the primary coil, to wirelessly induce an electromotive force (EMF) in a secondary coil. In a DWC system, the primary charging coils are laid on the road, forming a wireless charging lane, while the secondary coils are fitted at the bottoms of the EVs. Several circuits constitute this power transfer system, each of which needs to be optimally designed to maximize the power transfer efficiency from the mains grid to the EV battery while meeting the EV's energy demand. For DWC in particular, the objective is to efficiently deliver the necessary power required to compensate for the EV power consumption while adding to the overall state of charge (SoC) of the battery, which thereby increases the overall driving range. Accordingly, this requires optimal design of the charging coils, the compensation network components and the corresponding power electronic circuitry, which is the main scope of this work.

Lateral misalignment is another inevitable challenge, and hence a design consideration in DWC systems, due to the driving patterns of EV owners, particularly on extended straight routes. Studies on drivers' behavior reveal that an average lateral misalignment of $46 \mathrm{~cm}$ is observed when the driver is unaware of the study being conducted, and this value is only reduced to $26 \mathrm{~cm}$ once the driver is warned of being observed [11]. At $46 \mathrm{~cm}$ lateral misalignment, the authors in [7] report a reduction of almost $50 \%$ in the power transfer capability of the inductive link. This is in addition to the inherent longitudinal misalignment due to the vehicle's motion from one primary charging coil to the other. Hence, different misalignment tolerance strategies need to be implemented in order to enhance the power transfer capability of the wireless charging system during misalignments.

Several studies on the design of EV DWC systems are reported in the literature, addressing charging coils and compensation network designs, and the design of the electronic circuitry, aiming to improve the power transfer capability and misalignment tolerances of these on-road wireless chargers. The On-Line Electric Vehicle (OLEV) project demonstrates one of the earliest commercial deployments, reported in [8] to provide $80 \%$ power transfer efficiency at a $26 \mathrm{~cm}$ air gap at perfect alignment, using series-series (S-S) compensation networks. In their study [8], the authors emphasized the need for effective misalignment tolerance strategies to overcome the observed reduction in power transfer efficiency to $70 \%$ at $15 \mathrm{~cm}$ lateral displacement. Studies on the role of compensation networks are reported in $[2,12-14]$, in which the different topologies are compared in terms of their dependencies on coupling and loading conditions and their impacts on the resonance frequency. In particular, the authors in [13] compared the performance of different compensation topologies in terms of output voltage regulation and efficiency stabilization at different coupling conditions, i.e., different misalignments. Their results reveal that inductor-capacitor-capacitor (LCC)-LCC compensation networks are the most capable of providing a stable output voltage profile that is independent of variations in coupling and loading conditions. Details of the design and tuning of an LCC-LCC compensation network are presented in [9,10], in which the authors designed the components at off-peak coupling conditions, aiming to minimize voltage variations (in [9]) and maximize the power transfer efficiency (in [10]) over a range of 
coupling factor variations. In both studies, an average mutual coupling value was utilized for LCC network tuning based on the desired coupling variation range.

In contrast to off-peak compensation network tuning, DWPT system designs in [7,15-20] utilized closed-loop primary and secondary control to reduce fluctuations in output power at different coupling factors. In [7], power and current control loops were implemented on the primary side, offering improved efficiency and output power levels with up to $15 \mathrm{~cm}$ lateral misalignment. On the other hand, a secondary-side control system was proposed in [15,16]; it adjusts the secondary voltage levels to track the maximum power operating point of a S-S-compensated DWPT system at different coupling factor variations. The authors in [17] also proposed power control on the secondary side, aiming to simplify the primary-side circuitry by shifting the burden of power management to the secondary side. To leverage on the advantages of both primary and secondary side control loops and prevent primary side overload, a dual-side power control approach was adopted in [18] to avoid efficiency reduction at large coupling factor variations, also for a S-S-compensated WPT system. A similar approach was also adopted in [19] using LCC-S compensation, with the use of a low-latency communication link to guarantee real time information exchange between the primary and secondary sides. However, the utilization of an active communication link during the WPT process adds to the complexity of the system design and requires a detailed study of the different communication link parameters and the security of the information exchange process [2]. Accordingly, the authors in [20] implemented dual-side control loops independently, without the need for wireless communication between the primary and secondary sides.

Each of the aforementioned studies extensively addresses a single aspect of the DWPT system design to achieve output power stabilization, improved misalignment tolerance or maximum power transfer efficiency. Nevertheless, in order to simultaneously address all three objectives, this work integrates the different strategies addressed in those studies, including LCC-LCC network tuning and dual-side control, with a robust inductive link design, to leverage their corresponding advantages in improving the misalignment tolerance while addressing the maximum power and maximum efficiency objectives of dynamic wireless EV charging systems and acknowledging the EV energy demands. Hence, the main contributions of this paper can be summarized as follows:

- Deriving a simplified relationship between the maximum power and maximum efficiency operating points of an LCC-LCC-compensated WPT system, to be used for tuning the compensation components for improved misalignment tolerance.

- Providing a set of guidelines and design procedures for the design of a high power, high efficiency, misalignment tolerant EV DWC system, given a set of road and vehicle specifications, and a desired minimum received energy level to address the energy demands of a typical EV. This involves:

- Tuning the LCC compensation components to ensure resonance operation, maximum power transfer and a sufficiently high power transfer efficiency at variable coupling conditions.

- Improving the design of the inductive link to provide better coupling performance during misalignments.

- Implementing closed-loop primary-side and secondary-side control to track the maximum power operating point in different coupling conditions.

The rest of this paper is organized as follows. Section 2 presents detailed mathematical analysis of the output power and the power transfer efficiency of the LCC-LCCcompensated DWPT system. The top-level design scenario is then presented in Section 3, followed by details of the design process and algorithm in Section 4. Details of the inductive link design and the finite element method (FEM) simulations are described in Section 5. Final circuit-level analysis and simulations are then reported and discussed in Section 6 before the paper is concluded in Section 7. 


\section{Modeling and Analysis}

The block diagram of a typical inductive EV wireless charging system is shown in Figure 1, following the standardized stationary wireless EV chargers model presented in the SAE J2954 Standard [6].

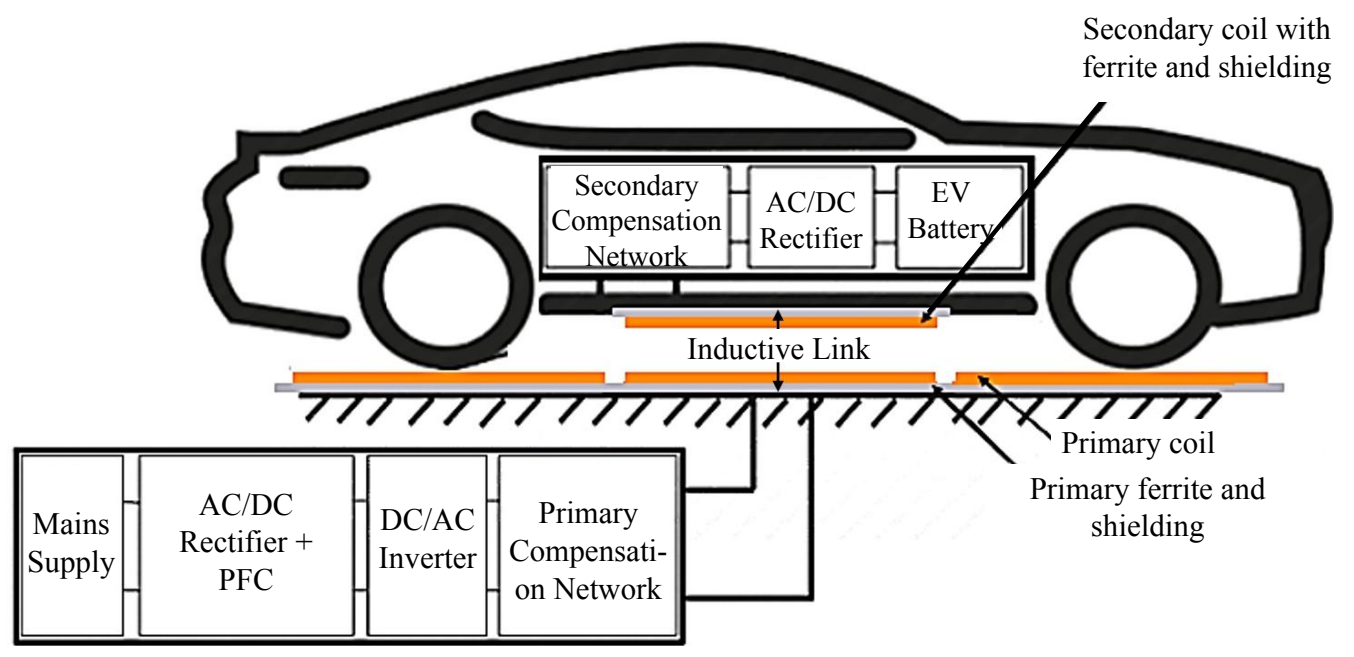

Figure 1. Block diagram of an EV wireless charging system.

This block diagram consists of several blocks that make up the wireless power transfer system. Starting from the primary side, electrical power from the mains supply is first rectified into a DC voltage to maximize its real power using an $\mathrm{AC} / \mathrm{DC}$ rectifier and a power factor correction circuit (PFC). This DC signal is then input into a high-frequency inverter to be up-converted to the operating frequency of interest. Compensation networks are then required to help operate the inductive link in resonance conditions. On the secondary side, an AC-DC rectifier is utilized after the LCC compensation, in order to convert the coupled AC power to DC power that can charge the EV battery. Between the rectifier and the battery, a DC/DC converter may be used to aid in the output power control process.

In order to evaluate the grid-to-vehicle power transfer efficiency of this wireless EV charging system, the efficiency of each block in Figure 1 needs to be studied. However, the design of the primary-side rectifier and power factor correction (PFC) circuits is extensively addressed in the literature for a wide range of applications [21-23] with no specific EV-related details in its design. Hence, it is out of the scope of this paper. In addition, grid-related issues, including grid supply-demand analysis and load balancing, are also widely studied in the literature [24-26]. While they mainly impact the overall grid energy management and EV charging coordination and billing, these issues do not particularly affect the specific design of the different components of the DWPT EV charging system shown in Figure 1. Accordingly, in this work, grid power is assumed to be readily available and the study of grid-related issues is left out of the scope of this paper.

As shown in Figure 1, the inductive link consists of the primary and secondary coils, and their corresponding ferrite and shielding layers. The compensation networks are required to resonate the primary and secondary sides at the desired operating frequency, to maximize the efficiency of the power transfer from the primary side to the secondary one. A suitable compensation topology for dynamic charging systems is one in which the secondary side current is independent of the secondary voltage and only depends on the input AC voltage, i.e., constant current source operation. This is achieved by both series-series and LCC-LCC compensation networks [27]. Nevertheless, the presence of an additional series inductor and a parallel capacitor in LCC topologies makes the load current directly proportional to mutual inductance, hence preventing overshooting currents in cases of misalignment [28]. This can be observed by studying the schematic of an LCC-compensated inductive link shown in Figure 2. 


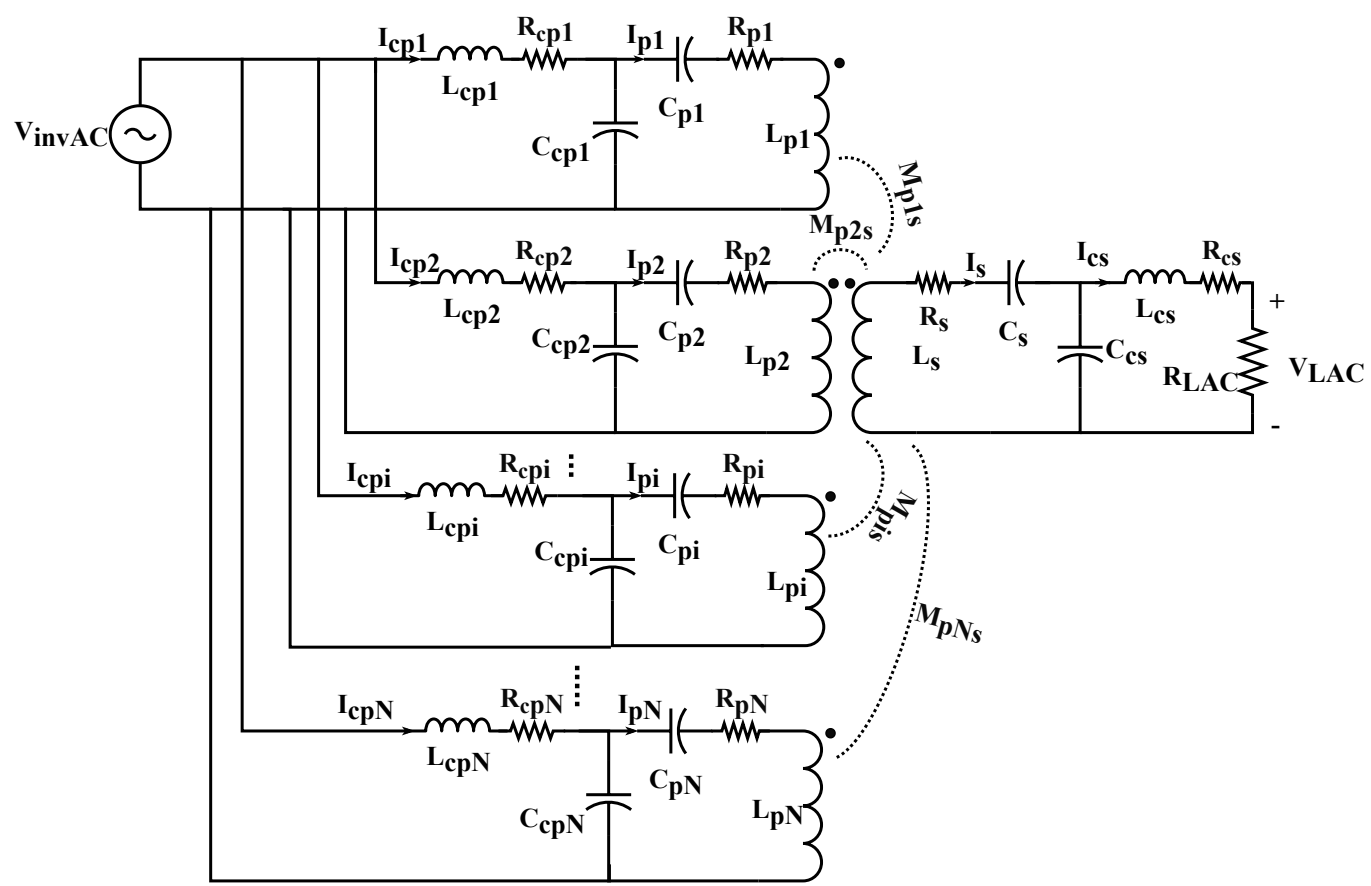

Figure 2. Schematic diagram of the inductor-capacitor-capacitor (LCC)-LCC-compensated inductive link.

The schematic in Figure 2 comprises $N$ primary circuits connected in parallel to a single sinusoidal voltage source, representing a DC/AC inverter, and a single secondary circuit corresponding to a single EV. The maximum number of primary circuits that can be connected in parallel to a single inverter is limited by the maximum current rating and power handling capability of the inverter. The design of the inverter power ratings is part of a higher-level optimization problem in which the available grid supply, the number of vehicles requesting charge at a time and the corresponding charging energy demand are all analyzed at a specific DWC system location to determine the required charging power levels and the corresponding lengths of the charging lanes [29]. This is, however, beyond the scope of this work. Accordingly, for the remainder of this paper, it is assumed that a single inverter connected to $N$ primary coils is used to supply power wirelessly to a single EV at a time, and the value of $N$ is selected based on the primary coil structure, as detailed in Sections 4 and 5 .

The input AC waveform, $V_{\text {inv } A C}$, is the fundamental harmonic of the output AC waveform of the inverter. It is connected to each primary coil, $L_{p_{i}}$, through an LCC compensation topology comprising a series compensation inductor, $L_{c p_{i}}$, with its equivalent series resistance (ESR); $R_{c p_{i}}$; a parallel compensation capacitor, $C_{c p_{i}}$; and a series compensation capacitor, $C_{p_{i}}$, where the subscript $i=1,2, \ldots, N$ is the index that maps to the corresponding primary coil. Each primary coil of inductance $L_{p_{i}}$ has an ESR of $R_{p_{i}}$.

The AC-DC rectifier on the secondary side together with the battery and other potential secondary side circuits are all modeled as an AC load resistance, $R_{L A C}$, connected to the secondary coil of inductance- $-L_{S}$-and ESR, $R_{S}$, through the corresponding secondary LCC compensation network $-L_{c s}, C_{c S}$ and $C_{S}$-and the ESR of the compensation inductor, $R_{c s}$. For better visibility, the dissipation resistors of the compensation capacitors are omitted from the schematic in Figure 2, but were included in the simulations conducted. The mutual coupling between the primary and secondary coils is denoted by $M_{p_{i} s}$ and is used with the coils' respective self inductances to calculate the coupling factor, $k_{p_{i} s}$ using the expression, $k_{p_{i} s}=\frac{M_{p_{i} s}}{\sqrt{L_{p_{i}} L_{s}}}$.

Without loss of generality and for the sake of simplicity, the following assumptions are made: 
1. Adjacent primary coils are placed at a sufficient separation distance, $D$, such that when the secondary coil is perfectly aligned on top of one of the primary coils, its mutual inductance with the previous and following coils is negligible [30]; i.e., $M_{p_{i} s}=0$ and $M_{p_{i+2} s}=0$ when $M_{p_{i+1} s}=M_{p s_{\max }}$ for $i=1,2, \ldots, N$ where $M_{p s_{\max }}$ is the mutual inductance at perfect alignment. This assumption is validated by the FEA simulation results reported later in this paper.

2. The distance $D$ is also large enough such that the mutual inductance between the two adjacent primary coils is very small and can be neglected.

3. All the primary coils are identical with same geometries, equal self-inductances and equal ESRs.

4. Each set of simultaneously active primary coils, hereafter referred to as a section of $N$ primary coils, is connected in parallel to the same sinusoidal inverter voltage, $V_{\text {inv } A C}$.

5. AC power from the mains grid is readily available for the dynamic EV wireless charging system.

6. The EV is traveling at a constant speed, $U$, along a flat $0 \%$ grade road. This is an expected regulation on DWC lanes that helps maximize the net energy received by the traveling EVs by avoiding an increased energy consumption during the acceleration/deceleration of EVs on the charging lanes.

7. The initial EV battery SoC, $S_{o} C_{i}$, for an EV demanding dynamic wireless charging falls between $20 \%$ and $\sim 90 \%$. This is required to ensure that the battery is charged in the constant current (CC) charging mode for a typical Li-ion battery [31].

It should be noted that EVs with $S_{0} C_{i}>90 \%$ are more effectively charged with a constant voltage $(\mathrm{CV})$ rather than a constant current. Nevertheless, since dynamic wireless charging (DWC) systems are mainly intended to address range anxiety of the EV drivers, EVs with $S_{o} C_{i}>90 \%$ are not expected to require DWC and are hence excluded from this study. Accordingly, only CC charging mode is assumed in this work.

Hence, acknowledging the aforementioned assumptions, the circuit in Figure 2 is analyzed as follows. By Faraday's law of induction, the electromotive force (EMF) induced across each inductor coil can be expressed in terms of the flux linkage $\lambda$ as $\varepsilon=\frac{d \lambda}{d t}$, where the flux linkage between mutually-coupled inductors is defined as $\lambda_{p_{i}}=L_{p_{i}} I_{p_{i}}-M_{p_{i} s} I_{s}$, and $\lambda_{s}=M_{p_{i} s} i_{p_{i}}-L_{s} i_{s}$. Accordingly, Kirchoff's voltage law (KVL) equations are derived for the schematic in Figure 2 in the frequency domain, while neglecting the ESRs of the coils for simplicity. The equations are as follows.

$$
\begin{gathered}
\mathbf{V}_{\mathbf{i n v A C}}=\left(j \omega L_{c p_{i}}+\frac{1}{j \omega C_{c p_{i}}}\right) \mathbf{I}_{\mathbf{c p _ { i }}}-\frac{1}{j \omega C_{c p_{i}}} \mathbf{I}_{\mathbf{p}_{i},} \\
j \omega M_{p_{i} s} \mathbf{I}_{\mathbf{s}}=\left(\frac{1}{j \omega C_{c p_{i}}}+\frac{1}{j \omega C_{p_{i}}}+j \omega L_{p_{i}}\right) \mathbf{I}_{\mathbf{p}_{i}}-\frac{1}{j \omega C_{c p_{i}}} \mathbf{I}_{\mathbf{c} \mathbf{p}_{i}}, \\
j \omega \sum_{i=1}^{N} M_{p_{i} \mathbf{s}} \mathbf{I}_{\mathbf{p}_{i}}=\left(j \omega L_{s}+\frac{1}{j \omega C_{c s}}+\frac{1}{j \omega C_{s}}\right) \mathbf{I}_{\mathbf{s}}-\frac{1}{j \omega C_{c s}} \mathbf{I}_{\mathbf{c s}}, \\
\mathbf{V}_{\mathbf{L A C}}=\frac{1}{j \omega C_{c s}} \mathbf{I}_{\mathbf{s}}-\left(j \omega L_{c s}+\frac{1}{j \omega C_{c s}}\right) \mathbf{I}_{\mathbf{c s}} .
\end{gathered}
$$

Hence, in order to maximize the power transferred from the primary side to the secondary side of the inductive link, the system needs to operate at a resonance frequency, $f_{0}$, such that minimum power is lost during the power transfer [32,33]. To achieve resonance, the values of $L_{c p_{i}}, L_{p_{i}}, C_{c p_{i}}$ and $C_{p_{i}}$ need to be designed such that the input impedance seen at the primary side is purely real and its reactive component is equal to zero-i.e., the input impedance has zero phase angle (ZPA) at $f_{0}$ and the corresponding angular resonance 
frequency, $\omega_{0}=2 \pi f_{0}$ [34]. The expression for the input impedance is derived in [34,35] for an inductive link with a single primary coil as follows:

$$
Z_{\text {in }}=j\left(\omega L_{c p_{i}}-\frac{1}{\omega C_{c p_{i}}}\right)+\frac{1}{\omega^{2} C_{c p_{i}}\left[\left(\omega M_{p_{i} s}\right)^{2} \omega^{2} R_{L A C} C_{c S}^{2}+j(A-B)\right]},
$$

where

$$
A=\omega L_{p_{i}}-\frac{1}{\omega C_{p_{i}}}-\frac{1}{\omega C_{c p_{i}}}
$$

and

$$
B=\omega C_{c S}\left(\omega^{2} L_{c s} C_{c s}-1\right)\left(\omega M_{p_{i} s}\right)^{2} .
$$

For the multi-primary inductive link setup assumed in this work, as shown in Figure 2, and since all the primary circuits are assumed to be identical with identical component ratings, the mutual inductance variable $M_{p_{i}}$ is assumed to incorporate the joint coupling between the primary and secondary sides. This includes coupling during the perfect alignment of the secondary coil with one primary coil and its partial alignment between two primary coils. Accordingly, the variable $M_{p_{i} s}$ is the mutual inductance profile of the overall system, incorporating both lateral misalignments of the secondary coil and its longitudinal displacement from one primary coil to another. This is reflected in the simulations described in the following sections of this paper.

Hence, by setting the imaginary component of $Z_{\text {in }}$ to zero, the values of the compensation components required to achieve resonance at the angular resonance frequency $\omega_{0}$ need to satisfy the following expressions $[19,34,36]$ :

$$
\begin{gathered}
\omega_{0}=\frac{1}{\sqrt{L_{c p_{i}} C_{c p_{i}}}}=\frac{1}{\sqrt{L_{c s} C_{c s}}}, \\
\frac{1}{\omega_{0} C_{c p_{i}}}=\omega_{0} L_{p_{i}}-\frac{1}{\omega_{0} C_{p_{i}}}, \\
\frac{1}{\omega_{0} C_{c s}}=\omega_{0} L_{s}-\frac{1}{\omega_{0} C_{s}} .
\end{gathered}
$$

It is observed in Equations (6)-(8) that in order to achieve resonance, the values of the compensation components are independent of $M_{p_{i} s}$ and $R_{L A C}$, which is required to ensure that the system remains in resonance despite variations in the coupling conditions during misalignment [27]. In addition, by substituting the resonance Equations (6)-(8) in (1)-(4), it is observed that the current through the primary coil, $\mathbf{I}_{\mathbf{p}_{i}}$, is independent of $M_{p_{i}}$ at resonance conditions, and only depends on the input AC voltage and the value of the compensation inductor, $L_{c p i}$. This means that for a constant $\mathbf{V}_{\text {invaC, }}$, the current through the primary coil is constant at a given value of the compensation inductor, which is important to ensure that the coil is operating at its rated current condition [28]. The current through the load, $\mathbf{I}_{\mathbf{c s}}$, is also constant for a constant $\mathbf{V}_{\text {invaC, }}$ and is independent of $R_{L A C}$ while only depending on the values of the compensation inductors. Nevertheless, it should be noted that the ZPA condition would be slightly relaxed during the design by phase, delaying the inverter current and making the circuit slightly inductive, to achieve the zero-voltage switching (ZVS) condition. This is required to minimize the switching losses of the MOSFET devices in the inverter [28,37].

The average power transferred to the load can be calculated using the expression $P_{R_{\text {LAC }}}=\mathbf{V}_{\mathbf{L A C}} \mathbf{I}_{\mathbf{c s}}$, which can be written in terms of inverter AC voltage, $\mathbf{V}_{\text {invAC, }}$ as:

$$
P_{R_{L A C}}=\frac{1}{\omega_{0} L_{c s}} \sum_{i=1}^{N} \frac{M_{p_{i} s}}{L_{c p_{i}}} V_{i n v A C} V_{L A C}
$$

As observed in (9), the output power is directly proportional to the mutual inductance $M_{p_{i} s}$, which highly improves the light load and no load conditions by decreasing the output 
power as the mutual inductance decreases. In addition, the dependence of $P_{R_{L A C}}$ on $L_{c p_{i}}$ and $L_{\mathcal{C}}$ makes the selection of these component values dependent on the maximum output power level required by the DWPT system.

Accordingly, based on the aforementioned analysis, the compensation components need to be designed such that the ZPA condition occurs only at a single value of $\omega_{0}$, for all variations in the coupling conditions, to maximize the output power while eliminating the current harmonics otherwise associated with frequency bifurcation. Frequency bifurcation is the condition in which the frequency to achieve ZPA is not unique [38], and it typically occurs with very small load resistance values [39]. In S-S-compensated power transfer systems, a limitation is imposed by the authors in [40-43] on the maximum allowed coupling factor to avoid frequency bifurcation, which is referred to as the critical coupling factor. However, for LCC-LCC-compensated networks, the additional compensation inductors, $L_{c p_{i}}$ and $L_{c s}$, introduce an additional degree of freedom that allows the system to be designed to eliminate frequency bifurcation without limiting the maximum required coupling factor. Accordingly, the values of $L_{c p_{i}}$ and $L_{c s}$ are calculated based on $k_{Z P A}$; the minimum coupling factor beyond which the ZPA condition is guaranteed to occur. Hence, by assuming that $L_{p_{i}}=L_{s}$ and $L_{c p_{i}}=L_{\mathcal{c}}$, the values of the compensation inductors can be calculated using:

$$
L_{\left.c\right|_{\text {Pmax }}}=\sqrt{\frac{k_{Z P A} L_{p_{i}} V_{i n v A C} V_{L A C}}{\omega_{0} P_{L A C_{\max }}}} .
$$

In addition, since the LCC-compensated topology in this work is desired to operate as a constant current source, the values of the compensation inductors are selected based on the desired constant output load current, $I_{\mathcal{C S}}$, by replacing the fraction $V_{L A C} / P_{L A C_{\max }}$ by $I_{\mathcal{C S}}$. Hence, the expression to calculate the value of the compensation inductor $L_{c}$ for constant current source design is given by:

$$
L_{\left.c\right|_{\text {CCmode }}}=\sqrt{\frac{k_{\mathrm{ZPA}} L_{p_{i}} V_{\text {invAC }}}{\omega_{0} I_{\text {SS }}}} .
$$

The selection of $k_{Z P A}$ for tuning the compensation inductors is addressed in $[9,10,44]$ using coupling factor averaging techniques. However, in this work, the authors propose to design the compensation inductors using the coupling factor for the desired misalignment tolerance level, i.e., by setting $k_{Z P A}=k_{\text {min }}$. Accordingly, this guarantees that the ZPA condition occurs only at $\omega_{0}$ for all $k>k_{\text {min }}$, and hence the transferred power is maximized over this coupling range.

In addition to maximizing the power received at the load, the power transfer efficiency of the LCC-LCC-compensated system needs to be evaluated. This is done by acknowledging the effect of the coil ESRs, and assuming the secondary coil couples with one primary coil at a time. The coil quality factors are defined as $Q_{p_{i}}=\frac{\omega_{0} L_{p_{i}}}{R_{p_{i}}}$ and $Q_{s}=\frac{\omega_{0} L_{s}}{R_{s}}$, representing the ratios of the coils' self inductance to their equivalent ESRs at the system operating frequency. Accordingly, the power transfer efficiency can be expressed in terms of $Q_{p_{i}}$ and $Q_{s}$ as follows:

$$
\eta_{A C}=\frac{k_{p_{i} s}^{2} Q_{p_{i}} Q_{s} R_{s} R_{L A C}\left(\omega_{0} L_{c S}\right)^{2}}{\left(\left(\omega_{0} L_{c S}\right)^{2}+R_{s} R_{L A C}\right)} \times \frac{1}{\left(\left(\omega_{0} L_{c S}\right)^{2}+R_{s} R_{L A C}\left(1+k_{p_{i} s}^{2} Q_{p_{i}} Q_{s}\right)\right)} .
$$

From (12), the expression $k Q=\sqrt{k_{p_{i} s}^{2} Q_{p_{i}} Q_{s}}$ can be used as a figure-of-merit (FoM) for the design of the primary and secondary coils. The higher the FoM, the higher the coupling and quality factors of the coils and the lower the losses in their ESRs.

Conventionally, the power transfer efficiency can be maximized by differentiating it with respect to $R_{L A C}$ to determine the optimum value of the load and the corresponding 
maximum achievable efficiency. By performing this differentiation operation, the expression of the optimum load, $R_{L A C_{\text {opt }}}$, is obtained as follows:

$$
R_{L A C_{o p t}}=\frac{\left(\omega_{0} L_{c s}\right)^{2}}{R_{s} \sqrt{1+k_{p_{i} s}^{2} Q_{p_{i}} Q_{s}}} .
$$

However, the value of $R_{L A C}$ is one of the design constraints specified by the desired maximum output power and constant output current levels, using the expression $R_{L A C_{\text {des }}}=\frac{8}{\pi^{2}} P_{\max } / I_{D C}^{2}$, where $I_{D C}$ is the DC battery current during CC charging mode, $P_{\text {max }}$ is the maximum output power and $\frac{8}{\pi^{2}}$ is the DC-AC impedance conversion factor assuming ideal diode rectifiers. Under this assumption, $I_{D C}$ can be related to $I_{C S}$ using $I_{\mathcal{~ S S}}=\frac{p i}{2 \sqrt{2}} I_{D C}$. Accordingly, Equation (13) can be re-arranged to obtain the optimal value of the coupling factor $k$ that maximizes the power transfer efficiency in terms of $R_{L A C_{d e s}}$, by assuming that $k_{p_{i} s}^{2} Q_{p_{i}} Q_{s} \gg 1$ and $Q_{p_{i}}=Q_{s}=Q$. The optimal value of $k$ is then obtained as follows:

$$
k_{p_{i} s_{\max \eta}}=\frac{\omega_{0}\left(L_{c s}\right)^{2}}{L_{s} \times R_{L A C_{\text {des }}}} .
$$

Acknowledging the aforementioned assumptions and by substituting $L_{c s}=L_{c||_{\max }}$ from (10) into (14), it can be observed that the condition for maximum power transfer, i.e., ZPA at constant current source operation, and that for maximum efficiency, can be related using

$$
\frac{k_{p_{i} s_{\max \eta}}}{k_{Z P A}}=\frac{V_{\text {inv AC }}}{I_{c S} R_{L A C_{\text {des }}}} .
$$

Hence, using (11) and (15), the effect of the compensation inductor design on the maximum transferred power and the AC-AC efficiency at maximum lateral misalignment is highlighted. The relationship established in (15) identifies the maximum power and maximum efficiency operating conditions based on the input-output voltage ratio. This is utilized to simultaneously address the misalignment tolerance, maximum power and maximum efficiency objectives of dynamic EV charging systems. In this work, $k_{Z P A}$ is selected to maximize the transferred power at the required misalignment tolerance, while setting a lower bound on the power transfer efficiency throughout the power transfer operation and maintaining high received power at the perfect alignment condition. This is further detailed in the design process in Section 4.

\section{Dynamic EV Charging Scenario}

While the sole objective of a static wireless charging system is to increase the SoC of the EV battery, dynamic wireless charging systems aim to compensate for the energy consumed by the EVs while on the move to prevent excessive depletion of the EV batteries and hence prolong the battery's lifetime [45]. Accordingly, to maximize the gains from dynamic charging, charging lanes need to be placed in urban areas with medium-range driving speeds such that the dependence on the EV battery is minimized for trips within the city boundaries where charging lanes are implemented. Ultimately, this translates into ensuring that the $\mathrm{SoC}$ at the end of the charging lane exceeds that at the beginning of the lane. In CC charging mode, and based on the design of the charging controller [46], the SoC levels can be linearly related, within the assumed SoC range from $20 \%$ to $90 \%$, to the energy consumed by the EV and the energy received from dynamic charging using the expression:

$$
\operatorname{SoC}_{f}=S_{o} C_{i}+\frac{E_{R x}-E_{c o n}}{E_{\max }} * 100,
$$

where $E_{R x}$ is the energy received from the DWPT system, $E_{c o n}$ is the amount of energy consumed by the EV as it traverses along the road and $E_{\max }$ is the maximum EV battery capacity. Let $T_{s}$ be the time taken by the EV to traverse along a charging lane of length 
$X_{\text {chg }} \mathrm{km}$. The energy received by the vehicle from the WPT system, at a constant velocity $U$, is calculated using:

$$
E_{R x}=\int_{0}^{T_{s}} P_{L A C}(t) d t=\frac{1}{U} \int_{x(0)}^{x(0)+X_{\text {chg }}} P_{L A C}(x) d x,
$$

where $P_{L A C}$ is the received power on the secondary side, obtained using (9), and $x$ is the direction of the forward motion of the EV. Accordingly, in order to incorporate the grid power supply for EV charging as a parameter in the design process, a lower bound on the received energy is required, at a minimum acceptable efficiency, to deem the design feasible and effective. The received electric energy $E_{R x}$ is not fully converted to mechanical energy due to the electrical losses of the EV motor. According to [47,48], these losses can be estimated to be around $10 \%-20 \%$, which means that the received energy from the DWPT system needs to be at least 1.25 times the energy consumed by the EV. In practice, however, it is desired to further increase the battery's SoC to allow the EV to travel over non-charging lanes without depleting its battery. Hence, within a city's infrastructure, it is suggested to implement charging lanes at equal separation distances around the city, such that the average distance traveled by the vehicle without charging is approximately equal to the total length of the deployed charging lanes. This requires receiving at least twice the vehicle's consumed energy over each charging lane, while accounting for the efficiency of the power transfer process. Hence, the energy design objective in this work is defined as follows:

$$
E_{R x_{\text {Des }}} \geq 2.5 \times E_{\text {con }} \text {. }
$$

This lower bound on the received energy addresses the ultimate objective of minimizing the utilization of the EV battery during urban city drives, and is used to determine the minimum required $\mathrm{AC}$ supply power to achieve this objective for any given set of lane and EV specifications, and inductive link parameters.

\section{Design Methodology}

Based on the aforementioned analysis, the design of the complete LCC-LCC-compensated wireless charging system involves the following key stages:

1. Definition of the charging lane and EV specifications.

2. Setting the energy design objective as per (18) using estimated $E_{c o n}$.

3. Design and FEM simulations of the inductive link to maximize FoM and improve misalignment tolerance.

4. Circuit-level design and simulations of the DWPT system to achieve the power, efficiency and misalignment tolerance objectives.

Following the analysis presented in Section 2, an optimized DWPT system design maximizes the power transferred at different misalignment conditions while maintaining a satisfactory power transfer efficiency. For this work, the minimum allowed AC-AC power transfer efficiency was set to $90 \%$. The choice of $k_{Z P A}$ for maximum output power was then initially set to the maximum allowed misalignment tolerance, and the circuit was simulated to verify that the received energy meets the objective in (18) while maintaining $\eta_{A C-A C} \geq 90 \%$ over the entire coupling range for $k>k_{Z P A}$. In case the received energy does not satisfy the energy design objective while high efficiency is maintained, $k_{Z P A}$ can be further reduced to allow higher power transfer at low coupling conditions, at the expense of a decrease in efficiency. Otherwise, if the efficiency condition is not met with the selected $k_{Z P A}, k_{Z P A}$ needs to be increased together with the maximum power limit $P_{\max }$ to provide the required energy to compensate for the $\mathrm{EV}$ consumption while achieving the minimum efficiency requirements. This is further clarified in the flow chart shown in Figure 3. 


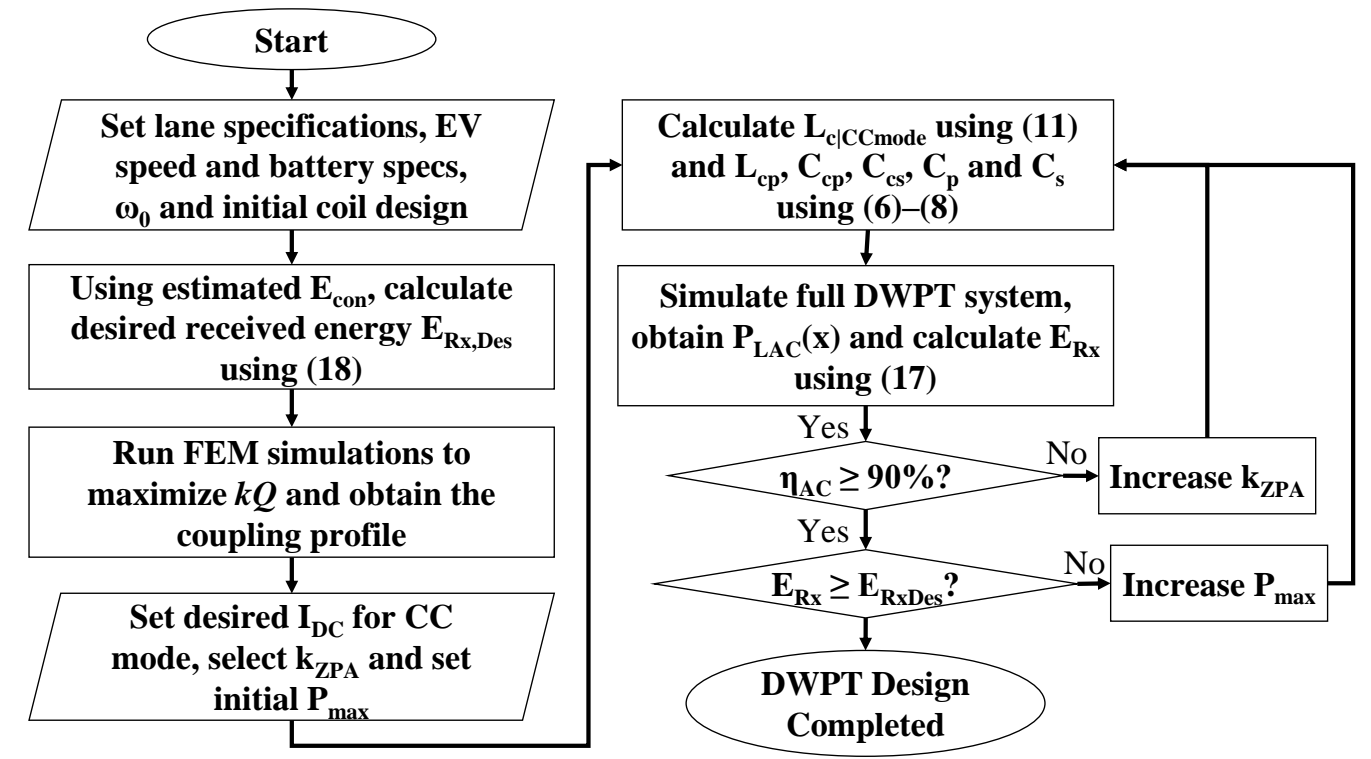

Figure 3. The dynamic wireless power transfer (DWPT) system's design algorithm.

\subsection{Charging Lane Design}

The deployment of dynamic charging lanes in a city infrastructure depends on the city's arterial network, traffic flow and traffic density at different times throughout a day, amongst several other factors [49]. Nevertheless, to demonstrate the design process proposed in this work, a simplified single lane charging scenario is used for the analysis. This consists of a single charging lane of length $X_{\text {chg }} \mathrm{km}$, with an average free-flow vehicle traveling speed of $U \mathrm{~km} / \mathrm{hr}$. The charging lane is divided into sections, each of which is powered from a dedicated inverter circuit. The design of each section depends on the structure of the primary coils, which can be a single elongated track per section or a segmented set of primary charging pads $[3,50,51]$. These are demonstrated in Figure 4 , where a single road section of length $S \mathrm{~km}$ can have $N$ primary coils, each of length $L$ and spaced by a distance $D$, or a single track primary coil of length $N L+(N-1) D$. In this work, the spacing between the adjacent sections is set to $L+D$ to allow for the on/off switching between the sections.

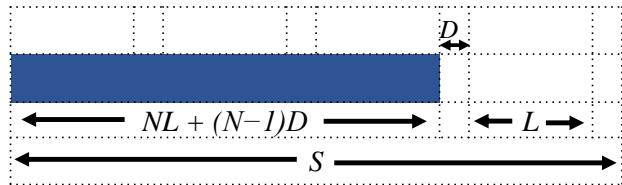

(a)

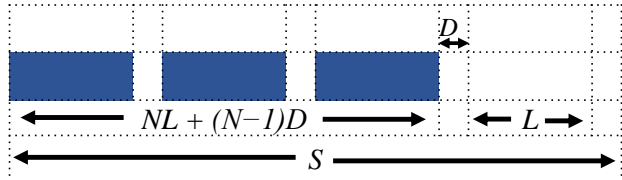

(b)

Figure 4. Primary coil structures per section: (a) track primary coil, (b) segmented primary coil.

As shown in Figure 4, the track primary coil is an elongated structure implemented such that a constant magnetic field is presented to the electric vehicle as it traverses along its length [50,52]. The length of this primary track is several times larger than the secondary coil embedded beneath the chassis of the EV, which is intended to provide a constant mutual inductance profile and enhance longitudinal misalignment tolerance. However, this structure causes significant power losses and safety concerns, due to stray fields occurring when only a single vehicle is traversing over the long track at a time. For a segmented primary structure, on the other hand, the size of each segment is comparable to that of the secondary coil embedded in the vehicle's body, which means that the length of a single section is almost equal to the length of a typical EV. This is expected to improve the coupling performance as it focuses the coupling magnetic fields within the area enclosed between the primary and secondary coils of comparable sizes. This accordingly reduces 
stray fields, minimizes field leakage to the surroundings and improves the power transfer efficiency $[3,51,53,54]$.

\subsection{Vehicle Specifications}

The EV model selected for this work was the Nissan Leaf 2019 model [55], whose dimensions, weight and other specifications are presented in Table 1 as reported in $[55,56]$ based on the recommended vehicle operation conditions.

Table 1. Specifications of EV model used in this work $[55,56]$.

\begin{tabular}{lll}
\hline Parameter & Symbol & Value \\
\hline Vehicle length & $l$ & $4445 \mathrm{~mm}$ \\
Vehicle width & $w$ & $1790 \mathrm{~mm}$ \\
Vehicle height & $h$ & $1560 \mathrm{~mm}$ \\
Vehicle wheel base & & $2700 \mathrm{~mm}$ \\
Gross vehicle mass (occupied) & $\mathrm{m}$ & $\approx 1900 \mathrm{~kg}$ \\
Maximum engine power & $P_{e}$ & $80 \mathrm{~kW}$ \\
Battery capacity & $\mathrm{C}$ & $40 \mathrm{kWh}$ \\
\hline
\end{tabular}

The EV energy consumption for the EV model in this work was estimated from U.S. Department of Energy report for baseline on-road testing of the Nissan Leaf at $70 \mathrm{~km} / \mathrm{h}$, zero acceleration and $0 \%$ road grade [57]. This was used to calculate the design objective using (18), and the corresponding values are reported in Table 2.

Table 2. DWPT system design objective.

\begin{tabular}{lll}
\hline Parameter & Symbol & Value \\
\hline Estimated energy consumption rate [57] & $E_{c o n}$ & $122.8 \mathrm{Wh} / \mathrm{km}$ \\
Minimum desired energy received, as per (18) & $E_{R x_{\text {Des }}}$ & $307 \mathrm{Wh} / \mathrm{km}$ \\
\hline
\end{tabular}

\section{Inductive Link Design and FEM Simulations}

The first step in designing the inductive link is to determine the resonant operating frequency, $f_{0}$, at which the inductive link shall resonate. The SAE J2954 standard [6] identifies $85 \mathrm{kHz}$ as the nominal operating frequency for static wireless electric vehicle chargers. Since a single secondary coil is expected to be fitted at the bottom of the EV, it is required to operate for both static and dynamic charging modes. Hence, $85 \mathrm{kHz}$ is proposed to be used as the operating frequency for dynamic wireless charging systems and is used for the design presented in this work. At $f_{0}=85 \mathrm{kHz}$, a heuristic design approach was followed using FEM simulations to optimize the dimensions, geometry and construction of the inductive link to maximize the $k Q$ FoM over a range of lateral misalignments. That is detailed as follows.

\subsection{Ferrite Layer}

The ferrite layer is a layer of ferrite material placed below the primary coil and on top of the secondary one, with a higher magnetic permeability than the copper used for coil construction. The main role of the ferrite layer is to intensify the magnetic fields between the two coils and hence increase the coupling factor, $k$, by increasing their mutual inductance. A ferrite material with high magnetic permeability, $\mu_{r}$, is required to minimize the dissipated energy and reduce core losses. In addition, the ferrite link geometry needs to be selected to provide enhanced coupling performance at different lateral misalignments. The ferrite layer specifications in this work follow the authors' earlier work in $[58,59]$ in which I-core ferrite bars with $\mu_{r}=3000$ provide satisfactory coupling performance over a wide range of lateral misalignments. These were used for all FEM simulations reported hereafter. 


\subsection{Shielding Layer}

In addition to the field enhancement provided by the ferrite layer, effective electromagnetic shielding is required to ensure that the magnetic field density surrounding the inductive link does not exceed the maximum allowed limit of $27 \mu \mathrm{T}$, as dictated by IEEE C95.1 standard [4] and ICNIRP guidelines [5]. In this work, an aluminum sheet was used as a shielding layer-specifically, aluminum 1050A alloy that has a conductivity of $\sigma=33.9 \mathrm{MS} / \mathrm{m}$ [41]. In order to ensure effective shielding, the thickness of the aluminum shield needs to be at least twice the skin depth of the aluminum alloy at the link operating frequency, $\omega_{0}$ [41]. This is because, after each skin depth of thickness, the field intensity is reduced by a factor of $\frac{1}{e}$, and hence twice the skin depth shall result in a more than $70 \%$ reduction in field intensity. The skin depth of aluminum alloy is calculated using $\delta=\sqrt{\frac{2}{\omega_{0} \mu_{0} \sigma}}$ to be approximately equal to $0.3 \mathrm{~mm}$. Nevertheless, to ensure effective shielding over a wide operating frequency range, the aluminum shield thickness is set to be six times the skin depth, i.e., $1.8 \mathrm{~mm}$, based on earlier work by the authors in [60]. In addition, to reduce eddy current losses in the aluminum shield, a vertical gap of $5 \mathrm{~mm}$ is maintained between the ferrite layer and the aluminum shield.

\subsection{Coil Design}

Using I-core ferrite bars and a $1.8 \mathrm{~mm}$ thick aluminum shield, the coil structure was designed and simulated to maximize the $k Q$ FoM over the widest range of lateral misalignments. Based on earlier studies [2,3], rectangular coils are proven to provide better magnetic flux distribution compared to circular coils and are less complex to design than double-D (DD) coils. In addition, planar coil structures provide better space efficiency in comparison with multi-layer designs. Hence, planar rectangular primary and secondary coils were selected for this work.

The size of the inductive link affects the self and mutual inductances of the coils, and according to [61], it needs to be proportional to the vertical separation distance, i.e., the air gap, between the coils. The area of the secondary coil in an EV charging system is restricted to the available space in the bottom chassis of the vehicle, and the vehicle-to-ground clearance is expected to be between $15 \mathrm{~cm}$ and $30 \mathrm{~cm}$ for most EVs. According to [62], a reasonable secondary coil occupancy is around $480,000 \mathrm{~mm}^{2}$ for a typical sedan EV. The outer charging pad dimensions, on the other hand, need to be larger to ensure effective shielding. This was selected to be $1000 \times 800 \mathrm{~mm}^{2}$. In addition, according to [63], the optimum value of the width of the coil is three times the height of air gap. Since the average air gap was estimated to be $\sim 200 \mathrm{~mm}$, the outer coil width was set to $600 \mathrm{~mm}$. Hence, for an area of $480,000 \mathrm{~mm}^{2}$, the outer length of the coil was set to $800 \mathrm{~mm}$.

Since the coils selected for the design of EV charging pads in this work were planar coils, the numbers of turns of the coils contributed to their self and mutual inductances, their ESRs and their coupling performance. A first-order approximation of Neumann's inductance calculation model is presented in [63], based on the geometric parameters of two air-core rectangular coils with no ferrite and aluminum shielding. Nevertheless, in order to account for the planar nature of the desired rectangular coils and the effects of the turn-to-turn spacing, ferrite and aluminum shielding layers, a set of FEM simulations was conducted on Maxwell simulator for different numbers of turns while setting $N_{p}=N_{s}$. The obtained results were fit onto the first order approximation model to obtain a corrected contour plot of coupling factor values at different primary and secondary turns. This is shown in Figure 5.

Accordingly, it was observed that for equal primary and secondary windings and dimensions, the rate of increase in coupling factor decreases as number of turns increases. This is shown in Figure 6.

Nevertheless, increasing the number of turns increases the amount of conductor wires used in coil construction and increases the ESR of the coil. The number of turns for both primary and secondary coils was then selected to be 16 based on earlier work by the authors 
in [60], as shown in Figure 6, and the coils' outer dimensions were set to $800 \times 600 \mathrm{~mm}^{2}$. The proposed inductive link design is summarized in Table 3.

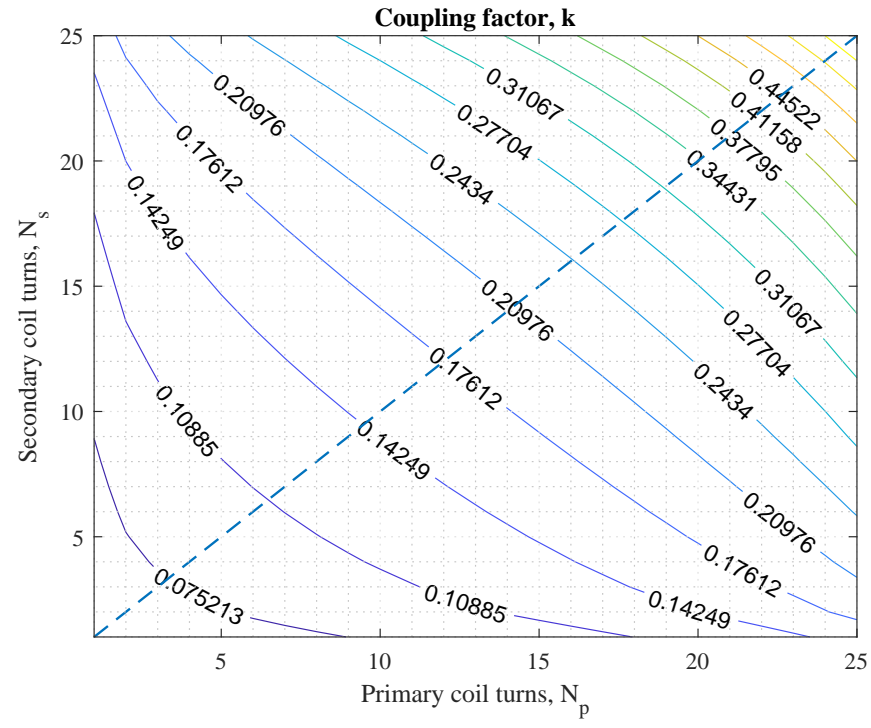

Figure 5. Contour plot showing the coupling factor, $k$, at different numbers of turns of primary and secondary coils.

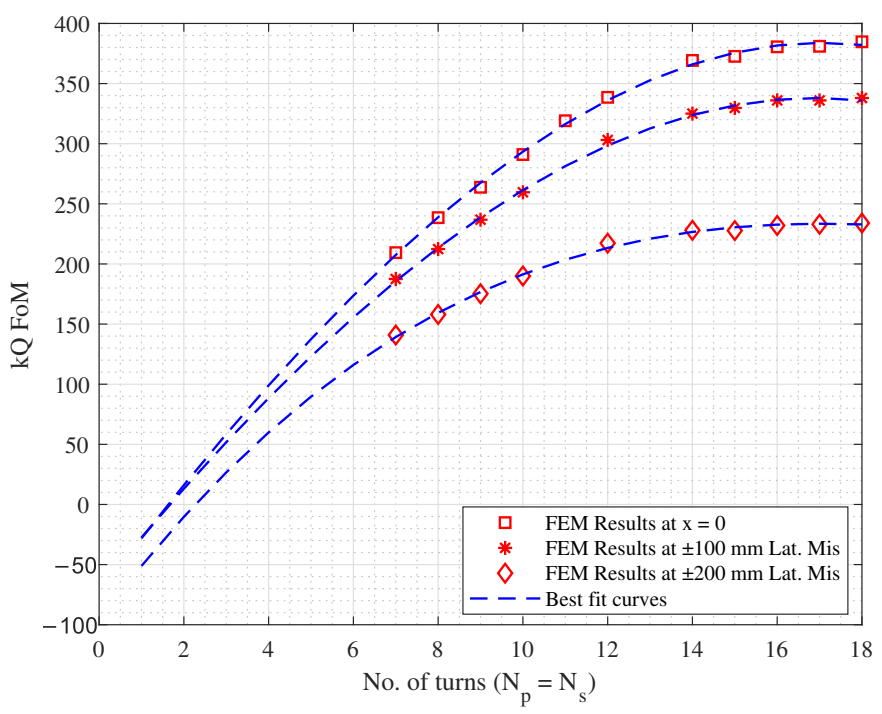

Figure 6. Variations in kQ figure-of-merit (FoM) with number of turns at different lateral misalignments (adopted from the author's earlier work in [60]).

Table 3. Dimensions and specifications of the coils.

\begin{tabular}{ll}
\hline Parameters & Value \\
\hline Coil surface area & $800 \times 600 \mathrm{~mm}^{2}$ \\
Number of turns & 16 \\
Wire diameter & $4 \mathrm{~mm}$ \\
Gross ferrite surface area & $900 \times 700 \mathrm{~mm}^{2}$ \\
No. of ferrite bars & 9 \\
Ferrite thickness & $16 \mathrm{~mm}$ \\
Gross aluminum surface area & $1000 \times 800 \mathrm{~mm}^{2}$ \\
Aluminum shield thickness & $1.8 \mathrm{~mm}$ \\
\hline
\end{tabular}

Using the dimensions in Table 3, the coupling profiles of the coils at different lateral 
misalignments were obtained as shown in Figure 7.

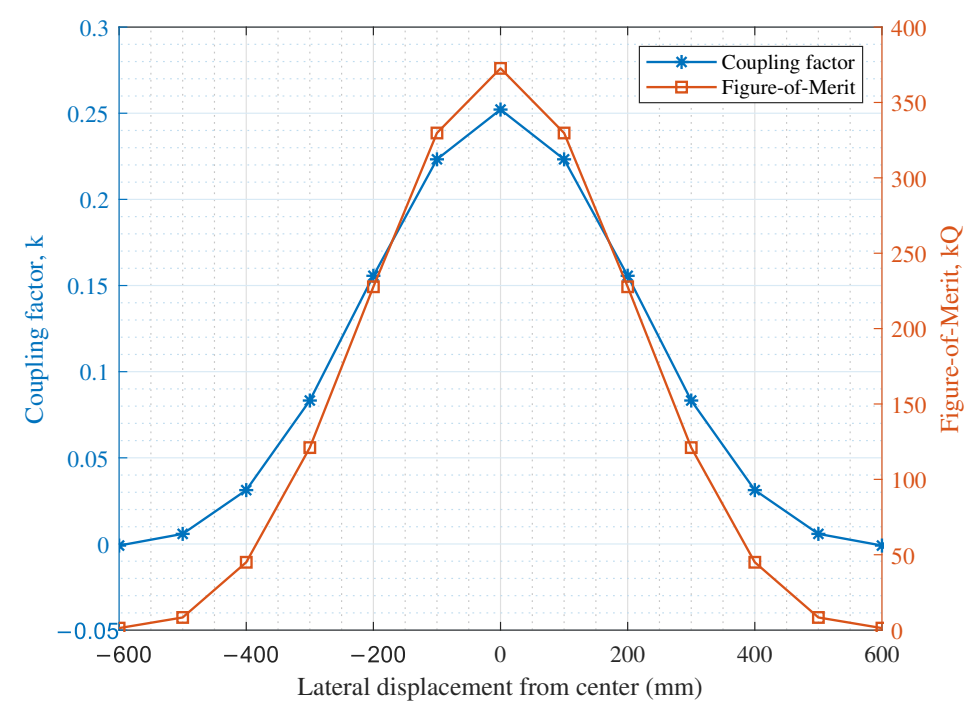

Figure 7. Coupling profiles of the proposed coils at different lateral misalignments.

A single road section was then constructed using the proposed inductive link design, following the structure in Figure $4 \mathrm{~b}$ with three primary coil segments with coil lengths of $800 \mathrm{~mm}$ and a coil-to-coil spacing of $100 \mathrm{~mm}$ while sharing a common aluminum shielding pad of length $2800 \mathrm{~mm}$. The corresponding track primary coil with the same outer area and same number of turns was also constructed and simulated. These are shown in Figure 8 and the corresponding coupling profiles are shown in Figure 9.

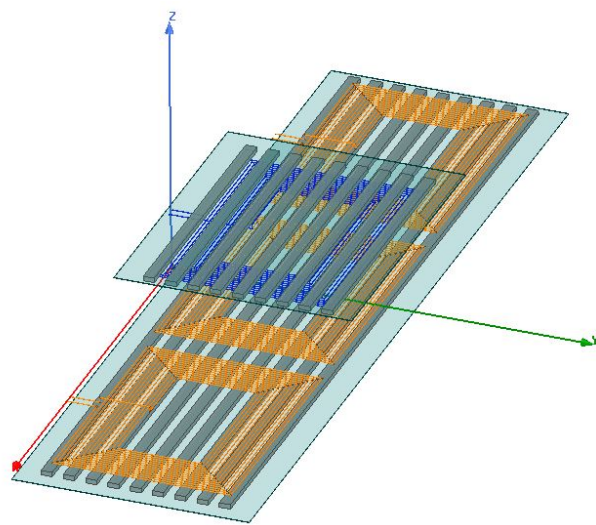

(a)

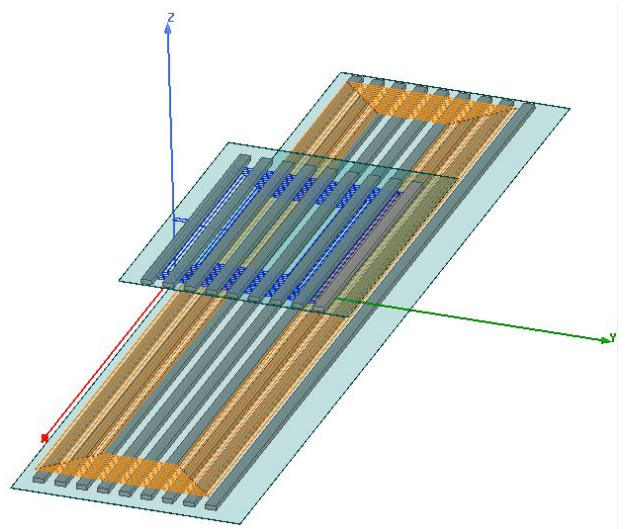

(b)

Figure 8. Primary coupler structures under investigation: (a) segmented primary coils, (b) track primary coils.

As shown in Figure 9, the segmented primary configuration meets the two design conditions defined in the assumptions listed at the beginning of this paper: $k_{p_{i} s} \approx 0$ and $k_{p_{i+2} s} \approx 0$ when $k_{p_{i+1} s}=k_{p_{i} s_{\max }}$ and $k_{p_{i} p_{j}}<\epsilon$ for $i \neq j$. In addition, it was observed that the coupling factor obtained with an elongated track primary coil was relatively constant, yet significantly smaller than that obtained using a segmented primary coil. This, as highlighted in Section 3, was due to the smaller flux linkage between the secondary coil and the longer track coil in comparison to equal-sized primary coil segments. This reduced flux linkage is due to the fact that the entire track provides a single flux path that only partially couples with the smaller secondary coil. Accordingly, mutual inductance is much smaller in comparison with the large self inductance of the track primary coil, and the coupling factor is low, as shown in Figure 9. Since the transmitted AC power is directly 
proportional to mutual inductance as per (9) and the received EV energy is the integral of the AC power received along the length of the track as per (17), the ratio of the received energy using segmented vs. track primary structures can be related to the area under their coupling profiles. Hence, by observing the area under the two coupling profiles in Figure 9, it can be concluded that the segmented primary coils shall provide higher received energy in comparison with track coils. Hence, segmented primary coil structures were selected for the DWPT system design presented in this work.

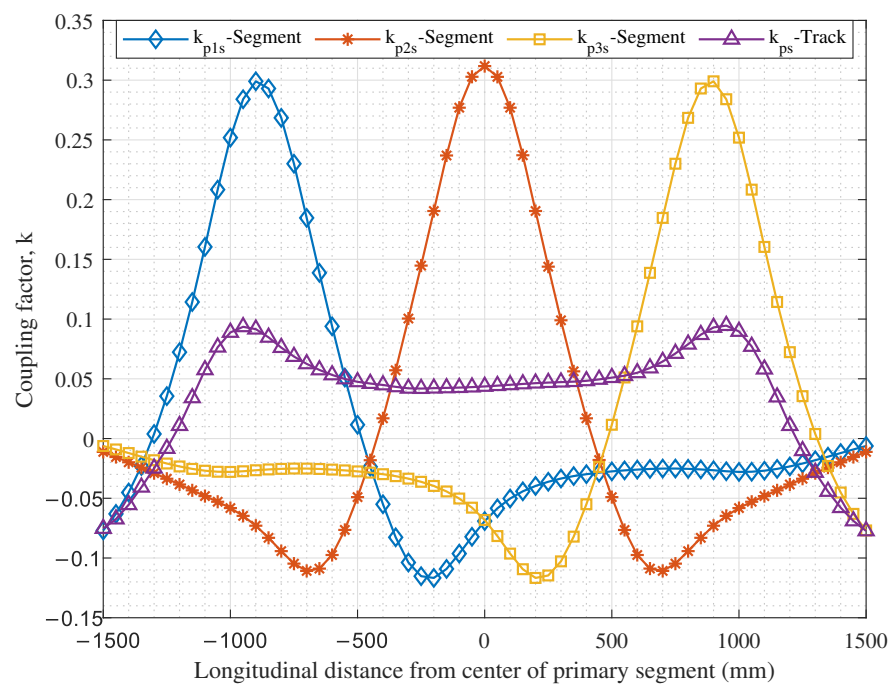

Figure 9. Coupling profile of the proposed 3-primary road segment: $k_{p_{1} s_{\text {segment }}}, k_{p_{2} s_{\text {segment }}}$ and $k_{p_{3} s_{\text {segment }}}$, vs. a single track primary segment, $k_{p s_{\text {Track }}}$.

\section{Circuit-Level Design and Simulation}

Once the inductive link design was finalized, FEM simulation results were exported into a circuit-level simulation on MATLAB/SIMULINK platform to simulate the operation of the compensation networks, the inverter and rectifier circuits and the EV battery together with the inductive link model. The inverter, rectifier circuits and control loops were designed first, and the EV battery was modeled; then the complete system was integrated and simulated accordingly.

The implementation of feedback control loops in the design of DWPT power electronic circuits is required to compensate for the variation of mutual coupling between the primary and secondary coils during the vehicle's motion, while providing the necessary limitations on the input/output currents to protect the circuit components. While LCC-compensated circuits are inherently tolerant to misalignments up to a certain extent, as explained in Section 2, feedback control loops are required, in addition to the compensation components' design, to allow tracking of the maximum power operating point of the system by maintaining ZPA operation at different coupling and loading conditions during the vehicle's motion. In this work, primary side control is implemented using inverter power and current control loops, inspired by the designs in [7,8,18-20], to achieve maximum power point tracking. On the secondary side, the controller is utilized to ensure that the output DC current does not exceed the constant charging current desired to charge the battery.

\subsection{Inverter Design and Control}

In the analysis presented so far, the input voltage was modeled as a sinusoidal waveform denoted by $V_{i n v A C}$, which represents the fundamental harmonic of the square wave output voltage of a class D DC-AC inverter. The duty cycle of the inverter square wave output voltage needs to be controlled to track the maximum power point at different coupling conditions. This is achieved by controlling the phase shift, $\varphi_{p}$, between the two inverter arms, which, in turn, controls the duty cycle $\theta$ and the magnitude, $v_{m}$, of the fundamental 
sinusoidal signal, $V_{i n v A C}$, and controls the output power of the inverter. The relationship between $v_{m}$ and $\theta$ is shown in the following expression $[7,64,65]$ :

$$
v_{m}=\frac{2 \sqrt{2}}{\pi} V_{i n D C} \sin \frac{\theta}{2}
$$

where $V_{i n D C}$ is the DC voltage input to the inverter, and the phase shift $\varphi_{p}$ and the duty cycle $\theta$ are related as $\theta=180-\varphi_{p}$ [66]. The feedback loops implemented to perform this primary-side phase shift control are shown in Figure 10.

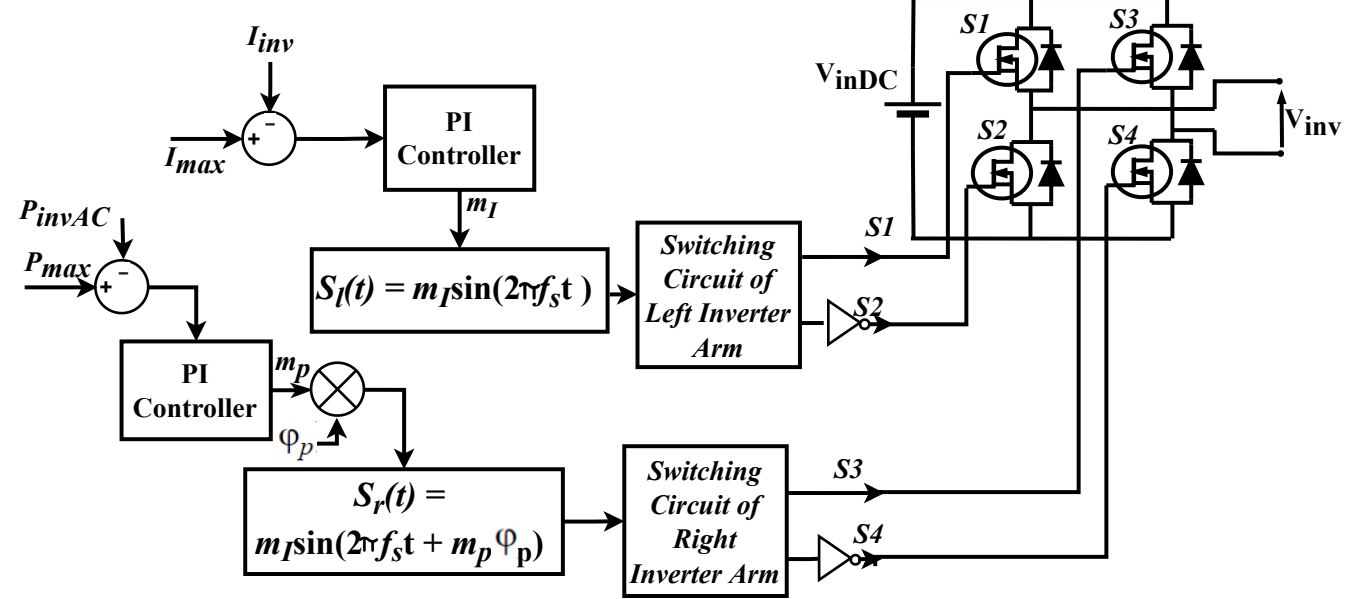

Figure 10. Control loops of the inverter switching circuit.

According to Figure 10, the inverter output power is compared to the desired system power level, $P_{\max }$, to track the maximum power operating point, and the error signal, $m_{p}$, is used to control $\varphi_{p}$ of the switching control signal $S(t)$, and hence control $\theta$ and the magnitude of the inverter voltage. Accordingly, a pulse-width-modulated (PWM) inverter is operated whose output power is controlled based on the desired maximum output power. In addition, the amplitude of the inverter current, $I_{i n v}$, is also compared with the maximum allowed current $I_{\max }$, based on the maximum current handling capability of the inverter MOSFETs, to generate the error signal $m_{I} . m_{I}$ modulates the amplitude of $S_{l}(t)$ and $S_{r}(t)$, the left and right switching control signals, with switching frequency $f_{s}$, while the power error signal, $m_{p}$, modulates the phase of $S_{r}(t)$ only to introduce the desired phase shift between the inverter arms. $S_{l}(t)$ and $S_{r}(t)$ are then compared with a triangular waveform at the same $f_{s}$ to generate the desired switching signals to the gates of the MOSFETs to provide the required power and current control.

\subsection{Rectifier Design and Control}

The conversion of the received $\mathrm{AC}$ waveform into a DC signal takes place through a rectifier-regulator pair, to provide a regulated DC output that can charge the EV battery. The input to the AC-DC conversion stage is a sinusoidal current, and a boost rectifier circuit is selected for this work to ensure operation in continuous current mode (CCM) [22] In particular, a symmetrical bridgeless boost rectifier topology was selected, as it provides reduced control complexity and a lesser number of active semiconductor devices per conduction path [67-69]. Nevertheless, the conventional model utilizes an inductor in the AC signal path, which adds to the value of the series compensation inductor, $L_{c s}$, and disturbs the resonance condition. In this work, the model was slightly modified by shifting the inductor to the DC side of the boost rectifier circuit, in order to perform the desired regulation function without disturbing the resonance of the system. This modification is demonstrated in Figure 11. 


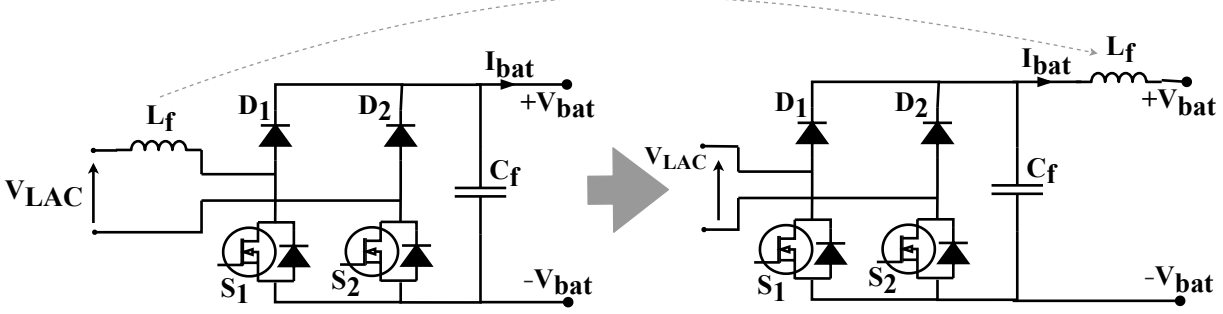

Figure 11. Modified symmetrical bridgeless boost rectifier.

As power control is implemented on the primary side of the proposed DWPT system, the key requirement for secondary side control is to ensure constant current is delivered to the EV battery to maintain CC charging mode with minimum current variations. This is implemented on the secondary side, and the control loop is implemented as shown in Figure 12.

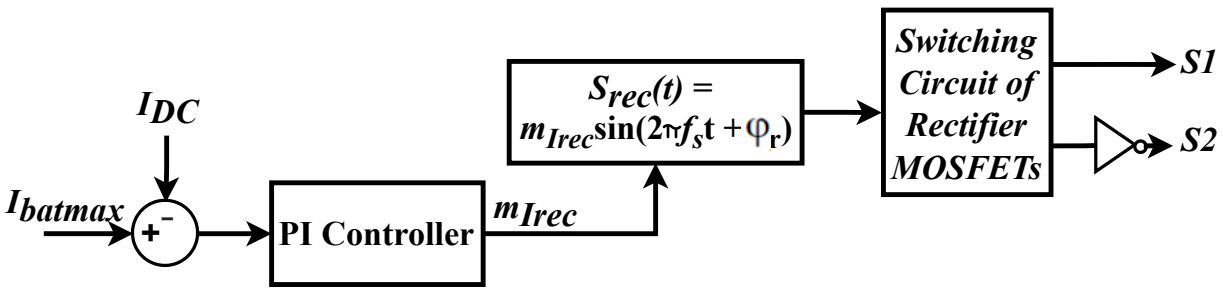

Figure 12. Control loop of the rectifier switching circuit.

As shown in Figure 12, the output current of the rectifier is compared with the desired constant DC battery current $I_{D C}$, and the current error signal, $m_{\text {Irec }}$, is used to modulate the switching control signal of the rectifier MOSFETs, $S_{\text {rec }}(t)$. The switching control signal is set to provide a phase shift of $\varphi_{r}=\pi / 2$ to the modified symmetrical bridgeless boost rectifier circuit, to maintain the phase characteristics and provide effective rectification of the boost rectifier, without disturbing the resonance condition.

\subsection{EV Battery Modeling}

Li-ion batteries are utilized particularly often for EV energy storage systems, as they offer high energy densities, good life cycle performance, low self-discharge and long service lifetimes $[70,71]$. While electrochemical and mathematical battery models exist in the literature [72,73], electrical models are the most suitable for circuit-level simulations and analysis, as they use an equivalent circuit model of the battery and incorporate its transient charging/discharging behavior [74].

Accordingly, a first-order Thevenin equivalent electrical model of a Li-ion cell was used to evaluate the performance of the proposed DWPT system on EV battery charging. The model consists of a constant open-circuit voltage, $V_{0}$, connected to an ohmic resistor, $R_{o}$, in series with a parallel RC network consisting of $R_{1}$ and $C_{1}$ that models the transient response of the battery. For the Nissan Leaf 2019 EV model selected for this work, the $40 \mathrm{kWh}$ battery is composed of two parallel modules, each consisting of $96 \mathrm{Li}$-ion cells with nominal voltage of $3.8 \mathrm{~V}[75,76]$. Accordingly, the EV battery was modeled on SIMULINK using the circuit shown in Figure 13, where $I_{b a t}$ is the charging current in each battery module and $I_{D C}=2 * I_{b a t}$ for the two $n$-cell battery modules in the Nissan Leaf 2019 battery pack. 


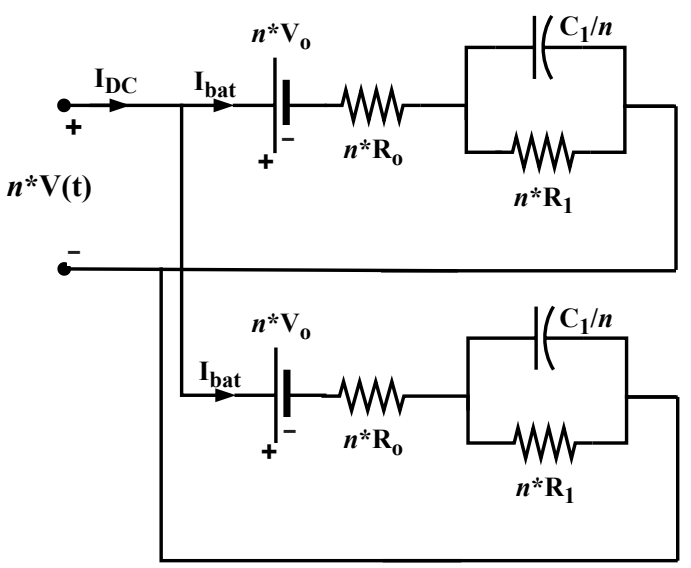

Figure 13. Two n-cell battery modules in parallel, where $n=96$ for the $40 \mathrm{kWh}$ Nissan Leaf battery model.

Based on the experimental analysis conducted in [75,77], the internal resistances of a Li-ion battery remain relatively constant within the SoC range assumed in Section 2, i.e., for $20 \% \leq S o C \leq 90 \%$. Hence, the values of $R_{o}$ and $R_{1}$ in Figure 13 are constants over the DWPT system operation range, and the value of $C_{1}$ is also constant for a particular battery time constant, $\tau=R_{1} C_{1}$, which can be determined by experimental battery testing. The open circuit equivalent voltage $V_{o}$, on the other hand, is dependent on the battery $\mathrm{SoC}$, and hence the values are obtained from look-up tables and/or graphs based on tests conducted for each battery model at different charging/discharging currents $[31,78,79]$.

\subsection{SIMULINK Test Bench}

With the primary and secondary control loops, the EV battery model and the inductive link design parameters, the complete DWPT system test bench was built on SIMULINK platform following the schematic in Figure 14.

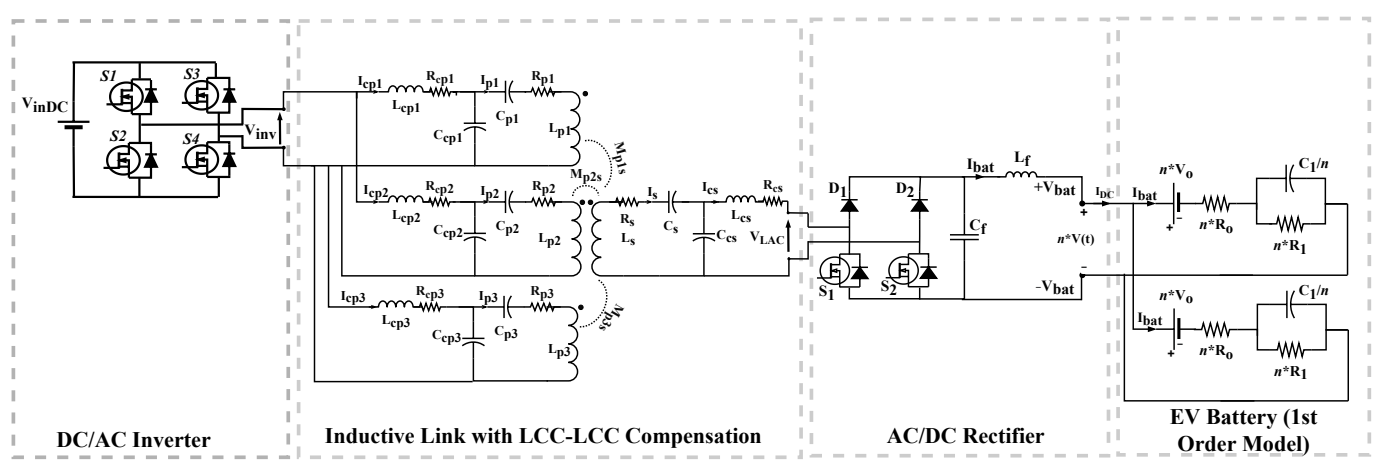

Figure 14. DWPT system schematic showing inductive link with compensation components, inverter and rectifier circuitry and an EV battery model (feedback control loops are omitted for simplicity).

The desired $P_{\max }$ was set to $40 \mathrm{~kW}$ with input DC voltage of $500 \mathrm{~V}$. A $40 \mathrm{~kW}$ power supply for EV charging lanes was considered reasonable, as it corresponds to an on-demand charging process in which the required power is drawn only as the vehicle passes over the charging coils. In fact, ongoing research and development efforts into DWPT EV charging systems have considered a power supply range from 20 to $100 \mathrm{~kW}$ based on the size of the vehicle, the air gap between transmitter and receiver coils, the power transfer efficiency and other factors $[7,8,80]$. Accordingly, the DWPT system ratings are summarized in Table 4. 
Table 4. DWPT system ratings used in SIMULINK test bench.

\begin{tabular}{lll}
\hline Parameters & Symbol & Value \\
\hline Rated system power & $P_{\max }$ & $40 \mathrm{~kW}$ \\
Input DC voltage rating & $V_{i n D C}$ & $500 \mathrm{~V}$ \\
Input DC current rating & $I_{\text {inDC }}$ & $80 \mathrm{~A}$ \\
Nominal DC battery voltage & $V_{b a t D C}$ & $364.8 \mathrm{~V}$ \\
EV battery capacity in Ah & $C$ & $110 \mathrm{Ah}$ \\
Battery charging current & $I_{D C}$ & $110 \mathrm{~A}$ \\
\hline
\end{tabular}

Accordingly, based on the self inductances of the primary and secondary coils obtained from FEM simulations and the corresponding ESRs and coupling profiles, the values of the compensation components were calculated using an initial value for $k_{Z P A}$ and the desired $P_{\max }$, as shown in the DWPT design algorithm in Figure 3 . The value of $k_{Z P A}$ was initially selected to be the coupling factor at a lateral misalignment of $\pm 200 \mathrm{~mm}$, i.e., $k Z P A \approx 0.15$, according to Figure 7. A summary of the components values is shown in Table 5.

Table 5. Component parameters in SIMULINK test bench.

\begin{tabular}{lll}
\hline Parameters & Symbol & Value \\
\hline Coupling coils' inductances & $L_{p_{i}}, L_{s}$ & $217.3 \mathrm{uH}$ \\
Series compensation inductors & $L_{c p}, L_{c s}$ & $14.82 \mathrm{uH}$ \\
Parallel compensation capacitors & $C_{c p}, C_{c s}$ & $236.6 \mathrm{nF}$ \\
Primary series compensation capacitor & $C_{p}$ & $17.32 \mathrm{nF}$ \\
Secondary series compensation capacitor & $C_{s}$ & $17.66 \mathrm{nF}$ \\
\hline
\end{tabular}

The frequency bifurcation phenomenon is first studied by plotting the phase of the input impedance evaluated using (5) for the compensation components' values calculated at $k_{Z P A}=0.15$. This is shown in Figure 15.

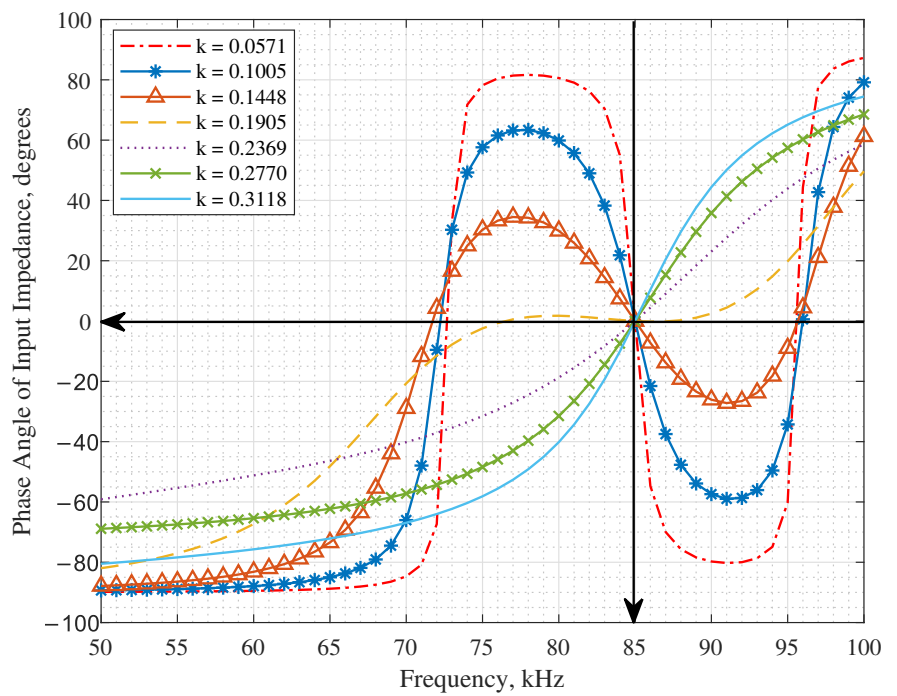

Figure 15. Phase plot of the input impedance $Z_{\text {in }}$ obtained using $k_{Z P A}=0.15$.

By observing the phase of the input impedance in Figure 15, it is noted that the ZPA condition occurs only at $\omega_{0}$ for all values of $k>k_{Z P A}$, and hence the frequency bifurcation effect is eliminated for the DWPT system designed for a lateral misalignment tolerance of $\pm 200 \mathrm{~mm}$. The next step is then to determine the amount of energy received by this system and its AC-AC power transfer efficiency to satisfy the remaining design objectives.

To simulate a realistic system operation, the ESRs of the compensation components also need to be acknowledged. The corresponding ESRs of the compensation inductors 
are estimated by assuming their quality factors to be equal to 750. A dissipation factor of $D F=0.1 \%$ is also assumed for the capacitors, from which their ESRs are calculated as $R_{c}=\frac{D F}{\omega_{0} C}$. The parameters of all circuit components are then used in the SIMULINK test bench, and the output power at different secondary coil positions is plotted and mapped to the corresponding coupling factors, as shown in Figure 16.

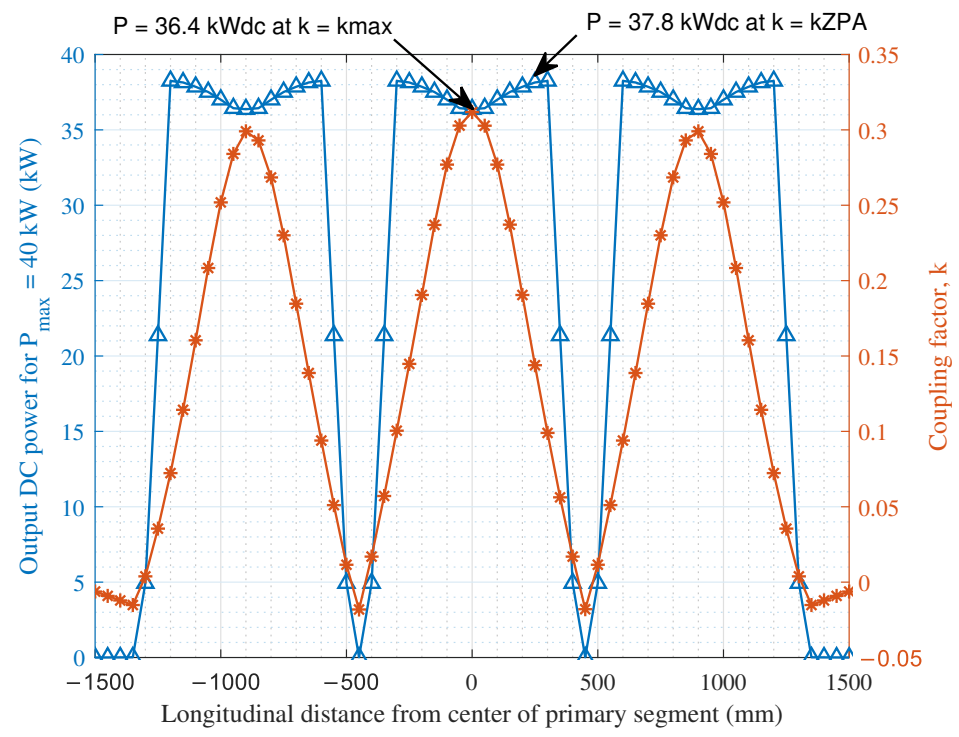

Figure 16. Output DC power profile using segmented primary structure for $P_{\text {max }}=40 \mathrm{~kW}$ and $k_{Z P A}=0.15$.

By observing the power profile in Figure 16, it is noted that the maximum power is transferred to the EV battery at $k_{Z P A}$ rather than at the maximum coupling point. This is essential to improving the misalignment tolerance of the DWPT by allowing higher output power levels at reasonably lower values of the coupling factor. The received power at $k_{\text {max }}$ is slightly lower, with a variation of only $3 \%$. This variation is acceptable as long as the received energy satisfies the EV requirements in Table 2 and the average overall efficiency is maintained above $90 \%$. The expected received energy in the EV battery is hence calculated by integrating the power profile in Figure 16, and the result is summarized in Table 6.

Table 6. Received energy of proposed DWPT system.

\begin{tabular}{ccc}
\hline Primary Structure & $E_{\boldsymbol{R} x} /$ Section & $\boldsymbol{E}_{\boldsymbol{R} x} / \mathbf{k m}$ \\
\hline Segmented primary structure & $1.156 \mathrm{Wh}$ & $308.2 \mathrm{Wh} / \mathrm{km}$ \\
\hline
\end{tabular}

The AC-AC power transfer efficiency of the proposed system design is shown in Figure 17.

Since the expected received energy per $\mathrm{km}$ exceeds the design objective in Table 2, and the average efficiency exceeds $90 \%$ for all regions of $k>k_{Z P A}$, the proposed system satisfies the requirements of a misalignment tolerant, dynamic, wireless EV charging system that both compensates for the EV energy consumption and increases the stored energy in the EV battery. In fact, the difference between the received energy per $\mathrm{km}$ from Table 6 and the EV energy consumption per $\mathrm{km}$ in Table 2 is the surplus energy that is stored in the EV battery to enable EV motion over road sections with non-charging lanes. Hence, by substituting these energy figures in the SoC calculation equation in (16), the battery SoC can be estimated to increase at a rate of $0.5 \%$ per $\mathrm{km}$ of on-road wireless charging cells in addition to the energy utilized for the motion. Nevertheless, Equation (16) is a simplified SoC estimation method and does not account for the battery temperature, aging and other factors that affect the battery energy levels. More sophisticated SoC estimation methods are reported in the literature [81] and shall be used in future work to further enhance the 
battery model. In addition, future enhancements of the proposed system model shall also include the coordination of the energy exchange between the EV motor and the EV battery, and the potential utilization of supercapacitors $[82,83]$ to ensure effective utilization of the energy received from the DWPT system.

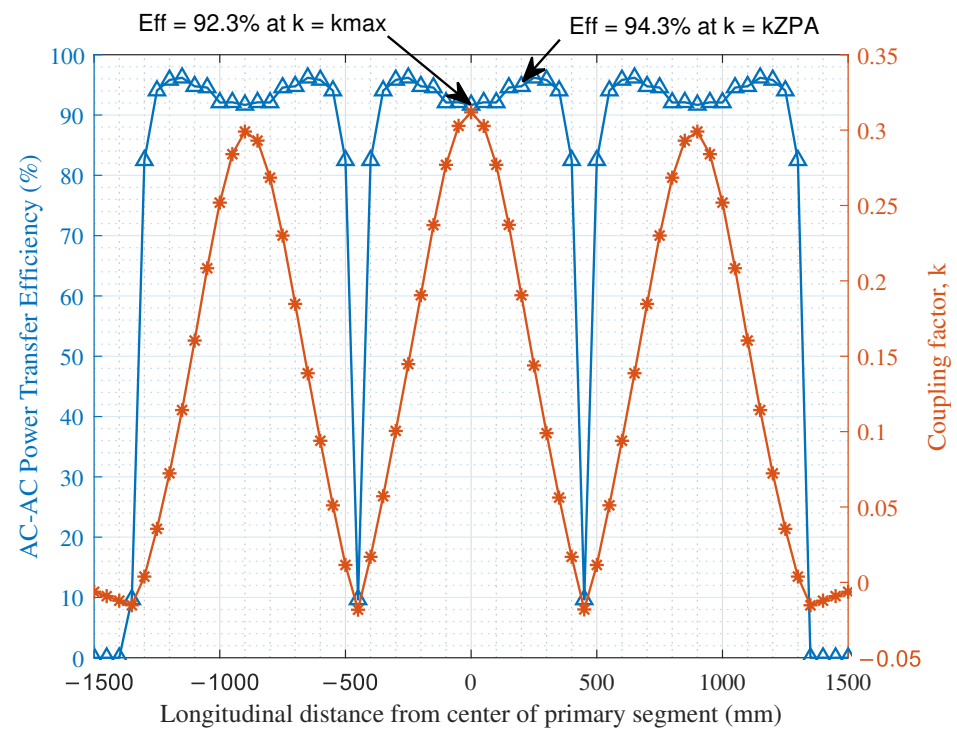

Figure 17. AC-AC power transfer efficiency for segmented primary structure for $P_{\max }=40 \mathrm{~kW}$ and $k_{Z P A}=0.15$.

Nevertheless, in order to assess the performance of the proposed system, the results presented in this section are compared with the reported results for other DWPT system designs in the literature $[9,10]$, as shown in Table 7.

Table 7. Comparison between proposed system and other DWPT charging systems.

\begin{tabular}{cccc}
\hline Reference & Ref. [9] & Ref. [10] & This Work \\
\hline Operating frequency & $140 \mathrm{kHz}$ & $50 \mathrm{kHz}$ & $85 \mathrm{kHz}$ \\
Compensation network & LCC-LCC & LCC-LCC & LCC-LCC \\
Operating power level & Not given & $2.5 \mathrm{~kW}$ & $40 \mathrm{~kW}$ \\
Coupling range & $0.18-0.32$ & Not given & $0.15-0.32$ \\
Tuning $k$ value & $\sqrt{k_{\min } k_{\max }}$ & $M_{\operatorname{lvg}} / L_{p} L_{s}$ & $k_{Z P A}=k_{\min }$ \\
Misalignment tolerance range & Not given & $0-10 \mathrm{~cm}$ & $0-20 \mathrm{~cm}$ \\
Load power variation & $15 \%$ & $8 \%$ & $3 \%$ \\
Efficiency at perfect alignment & $92.5 \%$ & $91.3 \%$ & $92 \%$ \\
Efficiency at maximum misalignment tolerance & $88.5 \%$ & $91.3 \%$ & $95 \%$ \\
\hline
\end{tabular}

As shown in Table 7 , while the presented system selects $k_{Z P A}$ for the maximum power point to be equal to the coupling factor at maximum allowed misalignment, the studies presented in $[9,10]$ both used an averaging equation to obtain their corresponding coupling factors to be used for tuning the compensation components. The objective of the authors in [9] was to minimize fluctuations in the voltage gain over the desired misalignment range, whereas the authors in [10] aimed to maximize the power transfer efficiency over that range. On the other hand, the work presented in this paper simultaneously addresses compensation network tuning, inductive link design and power electronic circuit analysis to achieve high misalignment tolerance, maximum power and maximum power transfer efficiency. The performance of the proposed system is hence superior to the other two systems in terms of the misalignment tolerance range, the maximum allowed power variations and the power transfer efficiencies at the maximum allowed misalignment point, while exhibiting comparable efficiencies at perfect alignment conditions. It is essential to 
highlight that the reported results from $[9,10]$ in Table 7 are mainly the results of the simulations conducted by the authors in both works, which thereby present a fair comparison to the results presented in this work.

\section{Conclusions}

This work demonstrates the design process of an LCC-LCC-compensated DWPT system for charging electric vehicles while maximizing the received power at different misalignment conditions and maintaining a sufficiently high power transfer efficiency. By leveraging the inherent misalignment tolerance capabilities of LCC-LCC-compensated systems, effective control loops were designed to ensure maximum power point tracking with minimal degradation in efficiency. While the proposed design utilizes a particular inductive link structure, the detailed design process presented in this work shall be effectively utilized for different inductive link designs given they have sufficiently high $k Q$ figures-of-merit. Accordingly, it is concluded that the optimal design of the DWPT system requires the design of the compensation components to satisfy the ZPA design objectives, while maximizing the $k Q$ FoM of the inductive link and tuning the respective power electronic circuitry to optimize the joint operation of the different system blocks. This paper serves as a guideline for DWPT system developers aiming to design functional dynamic EV wireless charging systems based on sets of design specifications and objectives.

Author Contributions: Conceptualization, E.E., M.S.H. and A.O.; methodology, E.E.; software, E.E.; validation, M.S.H. and A.O.; formal analysis, E.E.; investigation, E.E.; resources, M.S.H. and A.O.; data curation, E.E.; writing-original draft preparation, E.E.; writing—review and editing, M.S.H. and A.O.; visualization, E.E., M.S.H. and A.O.; supervision, M.S.H. and A.O.; project administration, M.S.H. and A.O.; funding acquisition, M.S.H. All authors have read and agreed to the published version of the manuscript.

Funding: This work is jointly supported by the American University of Sharjah through SCRI grant number SCRI 18-CEN-10, and by Sharjah Research Academy (SRA), Sharjah, United Arab Emirates.

Conflicts of Interest: The authors declare no conflict of interest.

\section{References}

1. Wu, H.H.; Gilchrist, A.; Sealy, K.D.; Bronson, D. A High Efficiency 5 kW Inductive Charger for EVs Using Dual Side Control. IEEE Trans. Ind. Inform. 2012, 8, 585-595. [CrossRef]

2. Patil, D.; McDonough, M.K.; Miller, J.M.; Fahimi, B.; Balsara, P.T. Wireless Power Transfer for Vehicular Applications: Overview and Challenges. IEEE Trans. Transp. Electrif. 2018, 4, 3-37. [CrossRef]

3. Ahmad, A.; Alam, M.S.; Chabaan, R. A Comprehensive Review of Wireless Charging Technologies for Electric Vehicles. IEEE Trans. Transp. Electrif. 2018, 4, 38-63. [CrossRef]

4. IEEE. Approved Draft Standard for Safety Levels with Respect to Human Exposure to Electric, Magnetic and Electromagnetic Fields, 0 Hz to 300 GHz-IEEE PC95.1/D3.5; IEEE: Piscataway, NJ, USA, 2019; pp. 1-312.

5. ICNIRP. Guidelines for Limiting Exposure to Time-Varying Electric and Magnetic Fields (1 Hz-100 kHz). Health Phys. 2010, 99, 818-836.

6. SAE International. Wireless Power Transfer for Light-Duty Plug-in/Electric Vehicles and Alignment Methodology. SAE J2954; SAE International: Warrendale, PA, USA, April 2019.

7. Tavakoli, R.; Pantic, Z. Analysis, Design, and Demonstration of a 25-kW Dynamic Wireless Charging System for Roadway Electric Vehicles. IEEE J. Emerg. Sel. Top. Power Electron. 2018, 6, 1378-1393. [CrossRef]

8. Shin, J.; Shin, S.; Kim, Y.; Ahn, S.; Lee, S.; Jung, G.; Jeon, S.; Cho, D. Design and Implementation of Shaped Magnetic-ResonanceBased Wireless Power Transfer System for Roadway-Powered Moving Electric Vehicles. IEEE Trans. Ind. Electron. 2014, 61, 1179-1192. [CrossRef]

9. Feng, H.; Cai, T.; Duan, S.; Zhao, J.; Zhang, X.; Chen, C. An LCC-Compensated Resonant Converter Optimized for Robust Reaction to Large Coupling Variation in Dynamic Wireless Power Transfer. IEEE Trans. Ind. Electron. 2016, 63, 6591-6601. [CrossRef]

10. Zhu, Q.; Wang, L.; Guo, Y.; Liao, C.; Li, F. Applying LCC Compensation Network to Dynamic Wireless EV Charging System. IEEE Trans. Ind. Electron. 2016, 63, 6557-6567. [CrossRef]

11. Green, P.; Cullinane, B.; Zylstra, B.; Smith, D. Typical Values for Driving Performance with Emphasis on the Standard Deviation of Lane Position: A Summary of the Literature. In Safety Vehicles Using Adaptive Interface Technology (Task 3A); U.S. Department of Transportation Volpe Center: Cambridge, MA, USA, 2004. 
12. Auvigne, C.; Germano, P.; Perriard, Y.; Ladas, D. About Tuning Capacitors in Inductive Coupled Power Transfer Systems. In Proceedings of the 2013 15th European Conference on Power Electronics and Applications (EPE), Lille, France, 2-6 September 2013; pp. 1-10. [CrossRef]

13. Lu, J.; Zhu, G.; Wang, H.; Lu, F.; Jiang, J.; Mi, C.C. Sensitivity Analysis of Inductive Power Transfer Systems With Voltage-Fed Compensation Topologies. IEEE Trans. Veh. Technol. 2019, 68, 4502-4513. [CrossRef]

14. Abou Houran, M.; Yang, X.; Chen, W. Magnetically Coupled Resonance WPT: Review of Compensation Topologies, Resonator Structures with Misalignment, and EMI Diagnostics. Electronics 2018, 7, 296. [CrossRef]

15. Hu, H.; Cai, T.; Duan, S.; Feng, H.; Zhang, X.; Niu, J.; Zhao, J. Constant Maximum Power Control for Dynamic Wireless Power Transmission System. In Proceedings of the 2017 IEEE PELS Workshop on Emerging Technologies: Wireless Power Transfer (WoW), Chongqing, China, 20-22 May 2017 ; pp. 295-299. [CrossRef]

16. Berger, A.; Agostinelli, M.; Vesti, S.; Oliver, J.A.; Cobos, J.A.; Huemer, M. A Wireless Charging System Applying Phase-Shift and Amplitude Control to Maximize Efficiency and Extractable Power. IEEE Trans. Power Electron. 2015, 30, 6338-6348. [CrossRef]

17. Hata, K.; Imura, T.; Hori, Y. Dynamic Wireless Power Transfer System for Electric Vehicles to Simplify Ground Facilities-Power Control and Efficiency Maximization on the secondary side. In Proceedings of the 2016 IEEE Applied Power Electronics Conference and Exposition (APEC), Long Beach, CA, USA, 20-24 March 2016; pp. 1731-1736. [CrossRef]

18. Diekhans, T.; De Doncker, R.W. A Dual-Side Controlled Inductive Power Transfer System Optimized for Large Coupling Factor Variations and Partial Load. IEEE Trans. Power Electron. 2015, 30, 6320-6328. [CrossRef]

19. Hu, X.; Wang, Y.; Jiang, Y.; Lei, W.; Dong, X. Maximum Efficiency Tracking for Dynamic Wireless Power Transfer System Using LCC Compensation Topology. In Proceedings of the 2018 IEEE Energy Conversion Congress and Exposition (ECCE), Portland, OR, USA, 23-27 September 2018; pp. 1992-1996. [CrossRef]

20. Khalilian, M.; Guglielmi, P. Charging Process Control of Dynamic Wireless Power Transfer System with Active Rectifier and without Wireless Communication System. In Proceedings of the 2018 IEEE 18th International Power Electronics and Motion Control Conference (PEMC), Budapest, Hungary, 26-30 August 2018; pp. 229-235. [CrossRef]

21. Garcia, O.; Cobos, J.A.; Prieto, R.; Alou, P.; Uceda, J. Single Phase Power Factor Correction: A Survey. IEEE Trans. Power Electron. 2003, 18, 749-755. [CrossRef]

22. Figueiredo, J.P.M.; Tofoli, F.L.; Silva, B.L.A. A review of Single-Phase PFC Topologies Based on the Boost Converter. In Proceedings of the 2010 9th IEEE/IAS International Conference on Industry Applications-INDUSCON 2010, Sao Paulo, Brazil, 8-10 November 2010; pp. 1-6. [CrossRef]

23. Yadav, A. A Literature Survey on Power Factor Correction using Boost Converter Rectifier-Cascaded with DC to DC Converter with Multiple Loads. Int. J. Creat. Res. Thoughts 2019, 6, 8.

24. Weckx, S.; Driesen, J. Load Balancing with EV Chargers and PV Inverters in Unbalanced Distribution Grids. IEEE Trans. Sustain. Energy 2015, 6, 635-643. [CrossRef]

25. Veldman, E.; Verzijlbergh, R.A. Distribution Grid Impacts of Smart Electric Vehicle Charging From Different Perspectives. IEEE Trans. Smart Grid 2015, 6, 333-342. [CrossRef]

26. Kikhavani, M.R.; Hajizadeh, A.; Shahirinia, A. Charging Coordination and Load Balancing of Plug-in Electric Vehicles in Unbalanced Low-Voltage Distribution Systems. IET Gener. Transm. Distrib. 2020, 14, 389-399. [CrossRef]

27. Li, W.; Zhao, H.; Deng, J.; Li, S.; Mi, C.C. Comparison Study on SS and Double-Sided LCC Compensation Topologies for EV / PHEV Wireless Chargers. IEEE Trans. Veh. Technol. 2016, 65, 4429-4439. [CrossRef]

28. Li, S.; Li, W.; Deng, J.; Nguyen, T.D.; Mi, C.C. A Double-Sided LCC Compensation Network and Its Tuning Method for Wireless Power Transfer. IEEE Trans. Veh. Technol. 2015, 64, 2261-2273. [CrossRef]

29. ElGhanam, E.A.; Hassan, M.S.; Osman, A.H. Deployment Optimization of Dynamic Wireless Electric Vehicle Charging Systems: A Review. In Proceedings of the 2020 IEEE International IOT, Electronics and Mechatronics Conference (IEMTRONICS), Vancouver, BC, Canada, 9-12 September 2020; pp. 1-7. [CrossRef]

30. Buja, G.; Bertoluzzo, M.; Dashora, H.K. Lumped Track Layout Design for Dynamic Wireless Charging of Electric Vehicles. IEEE Trans. Ind. Electron. 2016, 63, 6631-6640. [CrossRef]

31. Fang, Z.; Cai, T.; Duan, S.; Chen, C. Optimal Design Methodology for LLC Resonant Converter in Battery Charging Applications Based on Time-Weighted Average Efficiency. IEEE Trans. Power Electron. 2015, 30, 5469-5483. [CrossRef]

32. Yamaguchi, K.; Hirata, T.; Yamamoto, Y.; Hodaka, I. Resonance and Efficiency in Wireless Power Transfer System. WSEAS Trans. Circuits Syst. 2014, 13, 218-223.

33. Li, S.; Mi, C.C. Wireless Power Transfer for Electric Vehicle Applications. IEEE J. Emerg. Sel. Top. Power Electron. 2015,3 , 4-17.

34. Vu, V.; Tran, D.; Choi, W. Implementation of the Constant Current and Constant Voltage Charge of Inductive Power Transfer Systems With the Double-Sided LCC Compensation Topology for Electric Vehicle Battery Charge Applications. IEEE Trans. Power Electron. 2018, 33, 7398-7410. [CrossRef]

35. Lu, J.; Zhu, G.; Shou, Y.; Liu, F. Coupling- and Load-Independents Output Voltage and ZPA Operation in LCC-Series Compensated IPT System. In Proceedings of the 2018 IEEE Energy Conversion Congress and Exposition (ECCE), Portland, OR, USA, 23-27 September 2018; pp. 1172-1176.

36. Takeda, K.; Koseki, T. Improvement of Efficiency of Multi-Parallel Dynamic Wireless Power Transfer System with LCC Topology. In Proceedings of the IECON 2018 - 44th Annual Conference of the IEEE Industrial Electronics Society, Washington, DC, USA, 21-23 October 2018; pp. 4810-4815. [CrossRef] 
37. Mi, C.; Masrur, M. Hybrid Electric Vehicles: Principles and Applications with Practical Perspectives, 2nd ed.; John Wiley \& Sons: Hoboken, NJ, USA, 2017.

38. Zhang, W.; Mi, C.C. Compensation Topologies of High-Power Wireless Power Transfer Systems. IEEE Trans. Veh. Technol. 2016, 65, 4768-4778. [CrossRef]

39. Chen, Y.; Zhang, H.; Shin, C.; Seo, K.; Park, S.; Kim, D. A Comparative Study of S-S and LCC-S Compensation Topology of Inductive Power Transfer Systems for EV Chargers. In Proceedings of the 2019 IEEE 10th International Symposium on Power Electronics for Distributed Generation Systems (PEDG), Xi'an, China, 3-6 June 2019; pp. 99-104. [CrossRef]

40. Huang, R.; Zhang, B. Frequency, Impedance Characteristics and HF Converters of Two-Coil and Four-Coil Wireless Power Transfer. IEEE J. Emerg. Sel. Top. Power Electron. 2015, 3, 177-183. [CrossRef]

41. Kim, H.; Song, C.; Kim, D.; Jung, D.H.; Kim, I.; Kim, Y.; Kim, J.; Ahn, S.; Kim, J. Coil Design and Measurements of Automotive Magnetic Resonant Wireless Charging System for High-Efficiency and Low Magnetic Field Leakage. IEEE Trans. Microw. Theory Tech. 2016, 64, 383-400. [CrossRef]

42. Aditya, K.; Williamson, S.S. Design Guidelines to Avoid Bifurcation in a Series-Series Compensated Inductive Power Transfer System. IEEE Trans. Ind. Electron. 2019, 66, 3973-3982. [CrossRef]

43. Wang, C.-S.; Covic, G.A.; Stielau, O.H. Power Transfer Capability and Bifurcation Phenomena of Loosely Coupled Inductive Power Transfer Systems. IEEE Trans. Ind. Electron. 2004, 51, 148-157. [CrossRef]

44. Zhou, S.; Chris Mi, C. Multi-Paralleled LCC Reactive Power Compensation Networks and Their Tuning Method for Electric Vehicle Dynamic Wireless Charging. IEEE Trans. Ind. Electron. 2016, 63, 6546-6556. [CrossRef]

45. Garcia-Vázquez, C.A.; Llorens-Iborra, F.; Fernandez-Ramirez, L.M.; Sánchez-Sainz, H.; Jurado, F. Evaluating Dynamic Wireless Charging of Electric Vehicles Moving Along a Stretch of Highway. In Proceedings of the 2016 International Symposium on Power Electronics, Electrical Drives, Automation and Motion (SPEEDAM), Anacapri, Italy, 22-24 June 2016; pp. 61-66. [CrossRef]

46. Jeong, S.; Jang, Y.J.; Kum, D. Economic Analysis of the Dynamic Charging Electric Vehicle. IEEE Trans. Power Electron. 2015, 30, 6368-6377. [CrossRef]

47. Thomas, J. Drive Cycle Powertrain Efficiencies and Trends Derived from EPA Vehicle Dynamometer Results. SAE Int. J. Passeng. Cars Mech. Syst. 2014, 7, 1374-1384. [CrossRef]

48. Kieldsen, A.; Thingvad, A.; Martinenas, S.; Sorensen, T.M. Efficiency Test Method for Electric Vehicle Chargers. In Proceedings of the EVS29-International Battery, Hybrid and Fuel Cell Electric Vehicle Symposium, Montréal, QC, Canada, $19-22$ June 2016.

49. Li, M.; Wu, X.; Zhang, Z.; Yu, G.; Wang, Y.; Ma, W. A Wireless Charging Facilities Deployment Problem Considering Optimal Traffic Delay and Energy Consumption on Signalized Arterial. IEEE Trans. Intell. Transp. Syst. 2019, 20, 4427-4438. [CrossRef]

50. Zhang, W.; Wong, S.; Tse, C.K.; Chen, Q. An Optimized Track Length in Roadway Inductive Power Transfer Systems. IEEE J. Emerg. Sel. Top. Power Electron. 2014, 2, 598-608. [CrossRef]

51. Liang, X.; Chowdhury, M.S.A. Emerging Wireless Charging Systems for Electric Vehicles - Achieving High Power Transfer Efficiency: A Review. In Proceedings of the 2018 IEEE Industry Applications Society Annual Meeting (IAS), Portland, OR, USA, 23-27 September 2018; pp. 1-14. [CrossRef]

52. Tan, L.; Zhao, W.; Ju, M.; Liu, H.; Huang, X. Research on an EV Dynamic Wireless Charging Control Method Adapting to Speed Change. Energies 2019, 12, 2214. [CrossRef]

53. Liu, H.; Tan, L.; Huang, X.; Zhang, M.; Zhang, Z.; Li, J. Power Stabilization based on Switching Control of Segmented Transmitting Coils for Multi Loads in Static-Dynamic Hybrid Wireless Charging System at Traffic Lights. Energies 2019, 12, 607. [CrossRef]

54. Mazharov, N.; Hristov, S.; Dichev, D.; Zhelezarov, I. Some Problems of Dynamic Contactless Charging of Electric Vehicles. Acta Polytech. Hung. 2017, 14, 7-26. [CrossRef]

55. Nissan. Nissan Leaf. The Tech Advanced, 100\% Electric Car. Available online: https://www.nissan.co.uk/vehicles/newvehicles/leaf.html (accessed on 26 January 2020).

56. Nissan. Technical Specifications: 2019 Nissan Leaf S. Available online: https://www.auto123.com/en/new-cars/technicalspecs/nissan/leaf/2019/base/s / (accessed on 26 January 2020).

57. Idaho National Laboratory: Advanced Vehicles and Infrastructure Team. 2013 Nissan Leaf Advanced Vehicle Testing-Baseline Testing Results; Idaho National Laboratory: Idaho Falls, IA, USA, 2013.

58. Elghanam, E.A.; Kabalan, H.H.; Hassan, M.S.; Osman, A. Design and Modeling of Ferrite Core Geometry for Inductive Wireless Chargers of Electric Vehicles. In Proceedings of the 2019 International Conference on Electrical and Computing Technologies and Applications (ICECTA), Ras Al Khaimah, UAE, 19-21 November 2019; pp. 1-5. [CrossRef]

59. Elghanam, E.A.; Hassan, M.S.; Osman, A. Modeling, Simulation and Comparison of Different Ferrite Layer Geometries for Inductive Wireless Electric Vehicle Chargers. In Modelling, Simulation and Intelligent Computing. MoSICom 2020, Lecture Notes in Electrical Engineering; Goel, N., Hasan, S., Kalaichelvi, V., Eds.; Springer: Singapore, 2020; Volume 659, pp. 411-418.

60. ElGhanam, E.A.; Hassan, M.S.; Osman, A. Design and Finite Element Modeling of The Inductive Link in Wireless Electric Vehicle Charging Systems. In Proceedings of the 2020 IEEE Transportation Electrification Conference Expo (ITEC), Chicago, IL, USA, 24-26 June 2019; pp. 389-394.

61. Bosshard, R. Multi-Objective Optimization of Inductive Power Transfer Systems for EV Charging. Ph.D. Thesis, ETH ZURICH, Zürich, Switzerland, 2015. 
62. Nguyen, T.; Li, S.; Li, W.; Mi, C.C. Feasibility Study on Bipolar Pads for Efficient Wireless Power Chargers. In Proceedings of the 2014 IEEE Applied Power Electronics Conference and Exposition-APEC 2014, Fort Worth, TX, USA, 16-20 March 2014; pp. 1676-1682. [CrossRef]

63. Sallan, J.; Villa, J.L.; Llombart, A.; Sanz, J.F. Optimal Design of ICPT Systems Applied to Electric Vehicle Battery Charge. IEEE Trans. Ind. Electron. 2009, 56, 2140-2149. [CrossRef]

64. Liu, N. Design of a Universal Inductive Charging System for Electric Vehicles. Ph.D. Thesis, Georgia Institute of Technology, Atlanta, GA, USA, 2016.

65. Hasan, N.; Wang, H.; Saha, T.; Pantic, Z. A Novel Position Sensorless Power Transfer Control of Lumped Coil-based In-motion Wireless Power Transfer Systems. In Proceedings of the 2015 IEEE Energy Conversion Congress and Exposition (ECCE), Montreal, QC, Canada, 20-24 September 2015; pp. 586-593. [CrossRef]

66. Anyapo, C.; Teerakawanich, N.; Mitsantisuk, C. Development of Multi-Coils Full-Bridge Resonant Inverter for Dynamic Wireless Power Transfer. In Proceedings of the 2017 14th International Conference on Electrical Engineering/Electronics, Computer, Telecommunications and Information Technology (ECTI-CON), Phuket, Thailand, 27-30 June 2017; pp. 588-591. [CrossRef]

67. Jovanovic, M.M.; Jang, Y. State-of-the-Art, Single-Phase, Active Power-Factor-Correction Techniques for High-Power Applications-An Overview. IEEE Trans. Ind. Electron. 2005, 52, 701-708. [CrossRef]

68. Lim, J.-W.; Kwon, B.-H. A Power-Factor Controller for Single-Phase PWM Rectifiers. IEEE Trans. Ind. Electron. 1999, 46, 1035-1037. [CrossRef]

69. Cha, H.; Park, K.; Choi, Y.; Kim, R. Double-Sided LCC Compensation Topology with Semi-Bridgeless Rectifier for Wireless Power Transfer System. In Proceedings of the 2019 10th International Conference on Power Electronics and ECCE Asia (ICPE 2019-ECCE Asia), Busan, Korea, 27-30 May 2019; pp. 1-6.

70. Husain, I. Electric and Hybrid Vehicles: Design Fundamentals, 2nd ed.; Taylor \& Francis Group: Abingdon, UK, 2010.

71. Dai, H.; Zhang, X.; Gu, W.; Wei, X.; Sun, Z. A Semi-Empirical Capacity Degradation Model of EV Li-Ion Batteries Based on Eyring Equation. In Proceedings of the 2013 IEEE Vehicle Power and Propulsion Conference (VPPC), Beijing, China, 15-18 October 2013; pp. 1-5.

72. Wang, Q.; He, Y.; Shen, J.; Hu, X.; Ma, Z. State of Charge-Dependent Polynomial Equivalent Circuit Modeling for Electrochemical Impedance Spectroscopy of Lithium-Ion Batteries. IEEE Trans. Power Electron. 2018, 33, 8449-8460. [CrossRef]

73. Rong, P.; Pedram, M. An Analytical Model for Predicting the Remaining Battery Capacity of Lithium-ion Batteries. In Proceedings of the 2003 Design, Automation and Test in Europe Conference and Exhibition, Munich, Germany, 3-7 March 2003; pp. 1148-1149.

74. Cao, Y.; Kroeze, R.C.; Krein, P.T. Multi-Ttimescale Parametric Electrical Battery Model for Use in Dynamic Electric Vehicle Simulations. IEEE Trans. Transp. Electrif. 2016, 2, 432-442. [CrossRef]

75. Gray, T.; Wishart, J.; Shirk, M. 2011 Nissan Leaf VIN 0356 Plug-In Hybrid Electric Vehicle Battery Test Results; Report; U.S. Department of Energy: Washington, DC, USA, 2016.

76. Automotive Industry Portal Marklines. Nissan LEAF Teardown: Lithium-ion Battery Pack Structure. Available online: https:/ / www.marklines.com/en/report_all/rep1786_201811\#report_area_2 (accessed on 29 June 2020).

77. Yann Liaw, B.; Nagasubramanian, G.; Jungst, R.G.; Doughty, D.H. Modeling of Lithium-ion Cells-A Simple Equivalent-Circuit Model Approach. Solid State Ionics 2004, 175, 835-839.

78. Yao, L.W.; Aziz, J.A.; Kong, P.Y.; Idris, N.R.N. Modeling of Lithium-ion Battery using MATLAB/Simulink. In Proceedings of the IECON 2013-39th Annual Conference of the IEEE Industrial Electronics Society, Vienna, Austria, 10-13 November 2013; pp. 1729-1734.

79. Gong, X.; Xiong, R.; Mi, C.C. Study of the Characteristics of Battery Packs in Electric Vehicles With Parallel-Connected Lithium-Ion Battery Cells. IEEE Trans. Ind. Appl. 2015, 51, 1872-1879. [CrossRef]

80. Panchal, C.; Stegen, S.; Lu, J. Review of Static and Dynamic Wireless Electric Vehicle Charging System. J. Eng. Sci. Technol. 2018, 21, 922-937. [CrossRef]

81. Xiong, R.; Cao, J.; Yu, Q.; He, H.; Sun, F. Critical Review on the Battery State of Charge Estimation Methods for Electric Vehicles. IEEE Access 2018, 6, 1832-1843. [CrossRef]

82. Amjadi, Z.; Williamson, S.S. Prototype Design and Controller Implementation for a Battery-Ultracapacitor Hybrid Electric Vehicle Energy Storage System. IEEE Trans. Smart Grid 2012, 3, 332-340. [CrossRef]

83. Ristiana, R.; Rohman, A.S.; Machbub, C.; Purwadi, A.; Rijanto, E. A New Approach of EV Modeling and its Control Applications to Reduce Energy Consumption. IEEE Access 2019, 7, 141209-141225. [CrossRef] 